\title{
POTONCHÁN Y SANTA MARÍA DE LA VICTORIA: UNA PROPUESTA GEOMORFOLÓGICO/ARQUEOLÓGICA A UN PROBLEMA HISTÓRICO
}

\author{
Ulises ChÁveZ JimÉnEZ \\ ENAH-University of Calgary
}

\section{Introducción}

Una de las zonas poco exploradas y conocidas a nivel arqueológico en Tabasco, es la franja costera que abarca desde el río San Pedro y San Pablo al este del estado y en la frontera con Campeche, hasta el río Seco al norte, cerca de la barra de Tupilco.

Asimismo, uno de los parte aguas arqueológicos más importantes en el área ha sido la identificación en el contexto arqueológico de Potonchán y Santa María de la Victoria. El estudio de ambos sitios como asentamientos de coordenadas geográficas y cartográficas específicas, no ha podido ser abordado hasta ahora por la arqueología o la historia de manera precisa o multidisciplinaría, ya que metodológicamente plantea dos problemas un tanto difíciles de abordar.

1. Si se toman en cuenta las descripciones geográficas de una manera literal desde la geografía actual, la ubicación de ambos sitios será muy difícil de determinar, debido a que han intervenido factores geomorfológicos que han alterado la conformación del relieve de manera inequívoca, desde el siglo xvi a la fecha.

2. Respecto al contexto arqueológico, las descripciones históricas especifican que la arquitectura de la villa de la Victoria era de materiales perecederos. La presencia de plataformas y superficies acondicionadas puede ser posible, mientras que la ausencia de piedra y mortero ha dificultado la identificación de arquitectura en el registro arqueológico. En el caso de Potonchán, al erigirse una villa hispana sobre una capital provincial prehispánica, es lógico suponer que las estructuras prehispánicas hayan sido destruidas sistemáticamente y reutilizadas por parte de los españoles.

En cuanto al primer punto, cabe mencionar que para el estudio sistemático e integral de un sitio arqueológico es necesario entender y manejar la información referente a la formación no sólo del contexto arqueológico, sino de los suelos y la cambiante geografía de la región por estudiar, para una mejor interpretación de la información obtenida. A este respecto, en la costa de Tabasco, específica- 
mente en la región de Frontera, uno de los fenómenos naturales que dificultan tanto la identificación como la excavación de sitios arqueológicos es el proceso natural de modificación de la geomorfología en la formación de un sistema deltaico, como lo es el del río Grijalva. El entendimiento del fenómeno geomorfológico por el cual atraviesa toda el área de la barra principal de Frontera, es uno de los factores claves que ayudarán a establecer una mejor relación entre los fenómenos naturales y su participación en la formación de los contextos arqueológicos.

\section{El delta del Grijalva}

Un delta es definido como la acumulación de depósitos costeros de origen fluvial y eólico, producida por el arrastre de sedimentos a lo largo del cauce de un río. A su origen y desarrollo contribuyen aquellos depósitos sedimentarios moldeados por diversos agentes de origen marino, como el oleaje, las corrientes oceánicas y las mareas, con los que hacen contacto sobre la planicie costera. El proceso es simple: el río contribuye con sedimentos clásticos a la plataforma continental, de manera aún más rápida de lo que pueden ser removidos por los procesos de corrientes marinas. Un delta es una isla triangular formada en la desembocadura de algunos ríos; suele formarse por la acumulación de sedimentos fluviales y depósitos aluviales sobre los brazos cuando la corriente choca contra las aguas de un golfo o una albufera (Reading, 1986: 198). El complejo deltaico Grijalva-Mezcalapa-Usumacinta comprende el sistema estuarino de la costa mexicana del Golfo, que influye de manera determinante en las corrientes del Golfo de México por el importe-aporte de agua y sedimentos continentales, y representa una fuente importante de nutrientes y sedimentos para los suelos al interior del continente (Vélez, 1990: 12-15).

Los requisitos para una acumulación deltaica significativa es la existencia de un gran sistema fluvial que arrastre cantidades substanciales de sedimentos clásticos (éstos están compuestos por materiales producto del intemperismo físico depositados por los agentes de erosión, como fragmentos de rocas, cuarzos insolubles, feldespatos, minerales arcillosos, minerales precipitados a partir de materiales en solución acuosa). Dichos sistemas requieren una gran cuenca con un drenaje deficiente y abundantes precipitaciones anuales, como sucede a lo largo de la cuenca del río Grijalva.

El sistema hidrológico Mezcalapa-Grijalva-Usumacinta ha sufrido transformaciones sustanciales en su conformación geomorfológica. Es importante aclarar que dicho sistema dista mucho en la actualidad del sistema hidrológico conformado durante el siglo xvı. Entonces había tres sistemas hidrológicos perfectamente diferenciados: el del Grijalva, el del Usumacinta, y el del río Grande de Chiapas (o Mazapa, actualmente Mezcalapa —también Dos Bocas-, hoy río

Seco). El río Grijalva nacía y nace todavía en la Sierra Norte de Chiapas, donde 
parte de su curso corresponde con el de los ríos Tacotalpa y de La Sierra, y baja hacia Tabasco por el actual municipio de Tacotalpa. El río Mezcalapa era en el siglo xvi un tributario del Grijalva, proveniente del río Pantepec, en el noroeste de Chiapas. El Mazapa nacía y aún nace en Guatemala (en la provincia de Huehuetenango), atravesando el estado de Chiapas de oriente a poniente; cambiando su curso en dirección norte, hacia las llanuras aluviales de Tabasco. En el siglo xvI su principal cauce corría por el hoy llamado río Seco. En el siglo xvi el Mazapa, río grande de Chiapas o Dos Bocas, fue desviado hacia el oriente, de manera que su caudal alimentó al del Grijalva por medio del río Acachapan, con lo cual el río Grijalva se conectó también al original río Mezcalapa ${ }^{1}$ (Salazar, 2003).

En la actualidad se entiende que dichos sistemas hidrológicos no corresponden con aquellos del siglo xvı, y son considerados como un solo sistema fluvial, llamado Mezcalapa-Grijalva (figura 1), el cual cambia varias veces de nombre en el amplio circuito de su corriente. Actualmente se acepta que dicho sistema fluvial, conformado como unidad, tiene su origen en Guatemala, baja por la sierra de los Cuchumatanes, atravesando los estados de Chiapas y Tabasco, y pasa por las poblaciones de Chiapa de Corzo, Chicoacen y Huimanguillo, antes de entrar a las planicies aluviales de Tabasco, a su paso hasta la costa. Este sistema fluvial cubre un área total de $36566 \mathrm{~km}^{2}$.

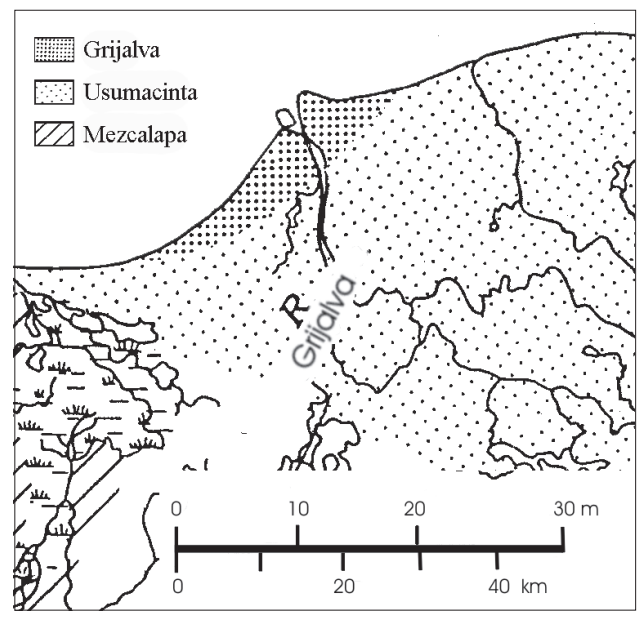

Figura 1. MAYores Sistemas deltaicos, formados en las recientes planicies costeras de Tabasco y Campeche Tomado de Psuty y West, 1969

\footnotetext{
${ }^{1}$ Es importante recalcar que la hidrología de Tabasco en la actualidad no es la misma hidrología que en el siglo xvi. Para un mejor acercamiento a la evolución de la hidrología de Tabasco, con excelentes conclusiones generales, estudiar el artículo de la antropóloga Flora Salazar Ledesma (2003) sobre el cambio en los sistemas fluviales, y el problema relacionado con su nomenclatura.
} 
El cauce principal y el de sus tributarios se han modificado a lo largo del tiempo por la formación de diques naturales, productos del azolvamiento y la sedimentación de arrastre en el cauce del río (West et al., 1969: 99), así como por obras de infraestructura humana temprana, hacia mediados del siglo xvII (Rovirosa, 1946: 15-20). Estas obras comprenden la desviación hacia el oriente del cauce principal del río Mazapa (el hoy río Mezcalapa) o Dos bocas (hoy río Seco) a la altura del ingenio Nueva Zelandia, en el actual municipio de Huimanguillo. A 84 kilómetros al norte de Villahermosa está la gran confluencia de "Tres Brazos", al cual sale el brazo más grandes del Usumacinta hacia el Grijalva; antes de su desembocadura, el Grijalva se alimenta del río Los Ídolos, el cual viene de las lagunas que comunican el gran brazo occidental del río Usumacinta. En este punto se unen los dos sistemas fluviales más importantes de la región, el Usumacinta y el Grijalva; integrando la corriente Grijalva-Usumacinta, que pasa 12 kilómetros arriba de su cauce por el puerto de Frontera, y sale 7 kilómetros más adelante en el Golfo de México, por la Barra Principal de Frontera (González, 1981: 48-73). Este sistema deltaico controla la red hidrográfica de las llanuras fluviales de Tabasco casi en su totalidad (West et al., 1969: 101 y 102).

Uno de los mayores cauces que alimentan al río Grijalva, es el cauce del río Mezcalapa. Una buena parte de su aporte sedimentario y de corriente afecta a su vez, al cauce y la corriente del río Grijalva. Se ha calculado (Krynine, 1939: 6) que su corriente es superior a los $80 \mathrm{~km} / \mathrm{h}$, ésta desciende transportando sedimentos semiconsolidados desde la sierra entre Chiapas y Tabasco, donde su nivel de erosión es de $20 \mathrm{~m}^{3}$ por hora durante la temporada de lluvias (Krynine, 1939: 7).

Más al norte, y antes de confluir en el sistema Grijalva-Mezcalapa, el río Mezcalapa erosiona varios metros cúbicos de arenisca de alta compactación durante aproximadamente tres meses al año, otorgando un aporte aún mayor al cauce del Grijalva previo a su desembocadura. Ya en ésta, se produce una fricción entre la corriente del río frente a la corriente marina, creándose canales bifurcados con barras continuas. La constante deposición lateral de sedimentos es relativamente lenta, pero como la profundidad del agua cercana a la desembocadura es baja, la potencia en la turbulencia de la corriente se restringe, y la fricción de las corrientes del fondo sobre la superficie se convierte en el factor causante de la desaceleración y expansión amplia de los sedimentos, lo que se traduce en un aumento en la velocidad de acumulación de éstos. Éste es otro factor importante en el desarrollo de nueva línea costera.

En algunas épocas el río Grijalva ha servido como tributario principal dentro de los llanos de Tabasco (West et al., 1969: 99-100), los cuales se componen en su totalidad de características costeras de barra. En el delta, la gran cantidad de sedimentos transportados hacia la costa, la poca pendiente del terreno y la disminución de la energía de las corrientes, permiten la formación de islas barrera, establecidas por la sucesión continua de cordones de playa de 
carácter regresivo, y favorecidas por una fuente constante de sedimento acumulado por corrientes de deriva costera. Tal dinámica de ambiente transicional facilitó la presencia de amplios ambientes lacustres, formados por las marismas y lagunas costeras de barrera. En el delta del Grijalva proliferan los pantanos de mucalería y popalería — vegetación propia de áreas anegadas y los terrenos secos próximos a las áreas pantanosas- (Santamaría, 1988: 311, 511), mientras que más allá de sus márgenes, colindando con los llanos y los confluentes levemente elevados, se abren paso las sabanas abiertas donde crecen pastos y juncos, matorrales y palmas (Ruz et al., 2000: 30-31). En la actualidad, la zona presenta una cobertura de manglares de $1890 \mathrm{~km}^{2}$, mientras que las superficies de marisma con halófitas se extienden sobre $3000 \mathrm{~km}^{2}$, y la superficie potencial de los pantanos (aquella donde la costa le gana tierra al mar) sobre $2580 \mathrm{~km}^{2}$. Debido al impacto de ascenso y descenso en el nivel de mar y el acarreo constante de sedimentos, la barra principal de Frontera se ha modificado sustancialmente. En su geografía visible en la actualidad, el sistema deltaico del río Grijalva cercano a su desembocadura presenta canales distributarios como los arroyos El Trapiche, Polo, El Coco y Tabasquillo; barras en la desembocadura como la isla El Buey y la a veces isla, a veces península, Punta del Buey; bahías interdistributarias como la bahía de la isla Punta del Buey y playa El Bosque; planicies costeras como las llanuras de Centla (Cintla); pantanos como los de Centla; y cordones de litoral, como aquellos presentes a lo largo de la costa del Golfo entre Campeche y Tabasco, en Laguna de Términos y Laguna de Mecoacán.

Hacia su desembocadura, el depósito de los sedimentos arrastrados por la corriente depende del tamaño de las diversas partículas que los componen. Las arenas se depositan rápidamente a una corta distancia de la desembocadura, mientras que las arcillas y los limos penetran mar adentro y se depositan en el área denominada "pro delta", la cual se ubica sobre el área que comprende el flujo del río penetrando a mar abierto. Con el tiempo las arenas depositadas en el área inmediata a la desembocadura tienden a invertir su deposición, debido al peso y el tamaño de las partículas, alternándose por partículas más finas y de menor tamaño.

La rápida expansión de sedimentos que conforman este tipo de deltas producen inicialmente un tipo de barra muy abierta y de forma radial. Sin embargo, conforme la deposición de sedimento en la barra continúa, en el fondo, capas de acumulación de sedimento se crean bajo los extremos laterales de los afluentes del delta, donde la velocidad es mayor. La formación de estas capas de sedimento tiende a inhibir un desarrollo posterior en la expansión de los afluentes, y provoca un crecimiento en el sistema de barra del río. Conforme la porción central de la barra crece, la aparición de canales a lo largo de su cauce tiende a seguir el curso entre las capas de acumulación de sedimento. Este proceso deriva en la formación de canales bifurcados triangulares, que la acción de la brisa costera se ocupa de mantener claramente definidos. Con el paso del tiempo estos 
canales se azolvan, y se produce la unión de éstos con tierra firme, lo que incrementa la línea de playa.

Como consecuencia de la suma de todos estos factores, se tiene que el sistema geográfico de las costas en Tabasco es un sistema muy dinámico. A veces las corrientes de los ríos son más fuertes que la presión ejercida por el Golfo de México, lo que deriva en el azolvamiento de sedimentos y en la consolidación de tierra firme por medio de los sistemas de barras. Es interesante observar que con un sistema tan dinámico de acumulación de sedimentos, el sistema GrijalvaMezcalapa-Usumacinta en su porción costera presenta modificaciones no observables a simple vista en la actualidad, por ejemplo, la formación de lagunas costeras por acumulación sedimentaria en lenguas de tierra, así como la aparición-desaparición de islas y lagunas; lo cual se puede comprobar históricamente con el constante retroceso y avance de la isla El Buey en Frontera.

Cabe mencionar que este tipo de eventos no es raro en el mundo (Gallico, 2000: 3). En Tabasco, por ejemplo, han existido siempre; en época de temporales la cantidad de agua y sedimentos arrastrados por los ríos, así como la fuerza de la corriente marina tienden a deformar el paisaje, y emergen o desaparecen porciones grandes de tierra. En 1999 los fenómenos de inundaciones en Tabasco confirmaron lo que la gente común en la región ha sabido desde siempre y nadie se ha molestado en describir o estudiar, el río, su delta y su historia; el agua tiene memoria.

\section{Implicaciones geomorfológicas en el contexto arqueológico del área próxima a la barra principal de Frontera}

El área de Frontera ha representado, a nivel de discusión y problemática histórica, uno de los parte aguas histórico-arqueológico más importantes de los últimos 100 años: la identificación de Potonchán y Santa María de la Victoria como dos de los sitios históricos más interesantes de Tabasco, ya que su ubicación no ha podido ser determinada.

Para el historiador, el uso de las fuentes históricas sirve de respaldo para una identificación geográfica de la ciudad prehispánica y la villa hispana; le permite identificar en la geografía moderna, y con base en los indicadores históricos, los posibles lugares donde yacen los restos de ambos asentamientos. Si se toman en cuenta las descripciones geográficas de una manera literal desde la geografía actual, la ubicación de ambos sitios será muy difícil de determinar, debido a que, como se ha dicho, han ocurrido fenómenos naturales geomorfológicos que han modificado el relieve de la región de manera determinante desde el siglo xvı a la fecha.

Como consecuencia inmediata en la arqueología, al investigar en las fuentes históricas la presencia de asentamientos costeros, se piensa inmediatamente en la costa visible en la actualidad, siendo que cualquier asentamiento supuesto 
como "costero" durante los siglos xvı y xvII en las fuentes, deberá de localizarse tierra adentro por sobre la línea de costa actual. Esto ha llevado a los investigadores y estudiosos de la arqueología y la historia —quienes nunca han recorrido el área o abordado los procesos geomorfológicos de la región costera de Tabasco y el río Grijalva como objeto de estudio- a obtener resultados con base en el uso de indicadores ambientales y arqueológicos poco confiables. La confiabilidad de estos resultados se obtiene en parte con la ayuda de las fuentes históricas, pero no sirve de nada ubicar sitios arqueológicos si no se entienden los procesos geomorfológicos bajo los cuales éstos fueron conformados hasta la actualidad.

Pertinente para este trabajo, es mencionar que para el estudio sistemático e integral de un sitio arqueológico es necesario entender y manejar la información referente a la formación no sólo en el contexto arqueológico, sino geomorfológico de la región por estudiar, para poder llegar a una mejor interpretación de la información obtenida. A este respecto, en la costa de Tabasco, específicamente en la región de Frontera, el mayor de los fenómenos naturales que dificultan la identificación y la excavación de sitios arqueológicos, es el proceso de modificación de los rasgos fisiográficos en el delta del Grijalva. Entender las variaciones geomorfológicas que ha sufrido el área de la barra principal de Frontera, es clave para establecer una mejor relación entre los fenómenos naturales y su participación en la formación de los contextos arqueológicos.

El propósito fundamental de este trabajo no es lograr la identificación de ninguno de los dos sitios referidos en las fuentes históricas, pero puede establecerse aquí parte del planteamiento necesario para su identificación. El entendimiento del problema geomorfológico planteado como parte de los antecedentes geográficos, contribuye a lograr un mejor plano geográfico, donde puedan aplicarse modelos de cartografía histórica. El desconocimiento de dicho modelo no lleva sino a incrementar la incertidumbre sobre la identificación de dichos sitios, ya que amplía el margen de error en los indicadores usados para tal propósito. De no atenderse esta sugerencia metodológica, cualquier sitio arqueológico excavado o no excavado en las proximidades a la desembocadura del Grijalva, puede potencialmente ser considerado como alguno de los sitios históricos mencionados en las fuentes, sin que necesariamente lo sea. Al parecer, la discusión abierta por Berlin en 1956, jamás podrá ser resuelta, ya que como anotó este autor, cualquier sitio arqueológico en la margen occidental del Grijalva con material cerámico posclásico, es potencialmente la Potonchán histórica.

Si se entiende que las características geomorfológicas del delta del Grijalva contribuyen a su constante transformación espacial, se puede hacer una reconstrucción parcial de la línea costera existente para 1519 y hasta la segunda mitad del siglo xVIII, cuando obras de infraestructura humana temprana, hacia 1765 (Rovirosa, 1946: 15-20), provocaron la desviación intencional hacia el oriente del cauce principal del río Mazapa — hoy río Mezcalapa—o Dos Bocas — hoy río Seco- , contribuyendo así al aporte masivo de sedimentos a la desembocadura 
del Grijalva, y acelerando un crecimiento sustancial en la línea costera del delta del Grijalva; lo que lleva a una búsqueda arqueológica en los lugares equivocados. Las características del sistema deltaico Grijalva-Usumacinta-Mezcalapa provocan que la línea costera del área de Frontera se modifique principalmente por el impacto del ascenso en el nivel de mar y el acarreo constante de sedimentos. El resultado es que a lo largo de los años y en un período relativamente corto (tal vez mucho menor a 400 años), el mar pierde terreno frente a las costas, debido al azolvamiento de sedimentos ricos en nutrientes, que derivan en zonas de sostenimiento de ecosistemas completos, convirtiéndose en pantanos y posteriormente en tierra firme de pastizales o bosques tropicales perennifolios.

Si hacemos revisión histórica de la cartografía de la época, desde el siglo xvi, durante el siglo xix y hasta la actualidad se puede observar que la modificación en el delta del Grijalva ha sido enorme: de acuerdo con apreciaciones propias, estimo que el delta ha crecido aproximadamente de 8 a 10 kilómetros mar adentro, y de 20 a 25 kilómetros a lo largo de la costa, reconfigurando el delta y el sistema de barras, y modificando el paisaje de la zona a tal grado que no concuerdan las descripciones histórico-geográficas con la cartografía actual del área en la barra principal de Frontera. No hay que dejar de considerar que la fuerza con la que penetraba para el siglo xvı el Grijalva mar adentro era "cosa de seis millas mar adentro", (Díaz, 1972: 66). Efectuado el rompido del siglo xvII a la altura de la ranchería Nueva Zelandia, toda la corriente que alimentaba al Mazapa cambió su curso y pasó a alimentar directamente el cauce del Grijalva, aumentando también la cantidad de sedimentos que después se habrían de acumular en su desembocadura, y azolvando ciertos ramales del mismo hasta convertirlo en un sistema de dunas y planicies costeras.

En pocas palabras, la búsqueda y excavación de cualquier sitio arqueológico supuesto como asentamiento costero durante el siglo xvı y hasta mediados del siglo xvIII, en las inmediaciones del río Grijalva, en realidad habría de realizarse tierra adentro, debido a que la línea costera moderna no coincide en lo absoluto con la costa de Tabasco hacia el período de contacto y hasta bien entrada la Colonia en México. La línea costera actual no existía cuando Cortés conquistó Tabasco, ni cuando los piratas destruyeron la primera capital hispana de la provincia. Cualquier búsqueda en la línea costera moderna en la Barra Principal de Frontera sería literalmente, como buscar una ciudad dentro del mar. Si realizamos un seguimiento histórico de la evolución de la Barra Principal de Frontera, a partir de mapas cartográficos existentes para el área, desde 1570 y hasta el año 2000, podemos observar la evolución del delta del río Grijalva, y proponer a su vez la delimitación de la región costera de Tabasco para el siglo xvi. Las figuras de la 2 a la 7 han sido tomadas del Atlas histórico de Tabasco (Guzmán, 1982), la figura 8 pertenece al INEGI. Año 2000, escala 1: 50000 . La figura 9 es la propuesta del modelo geomorfológico sobre la evolución del delta del Grijalva, y el área de terreno ganado al mar desde 1519, elaborado por el autor. 


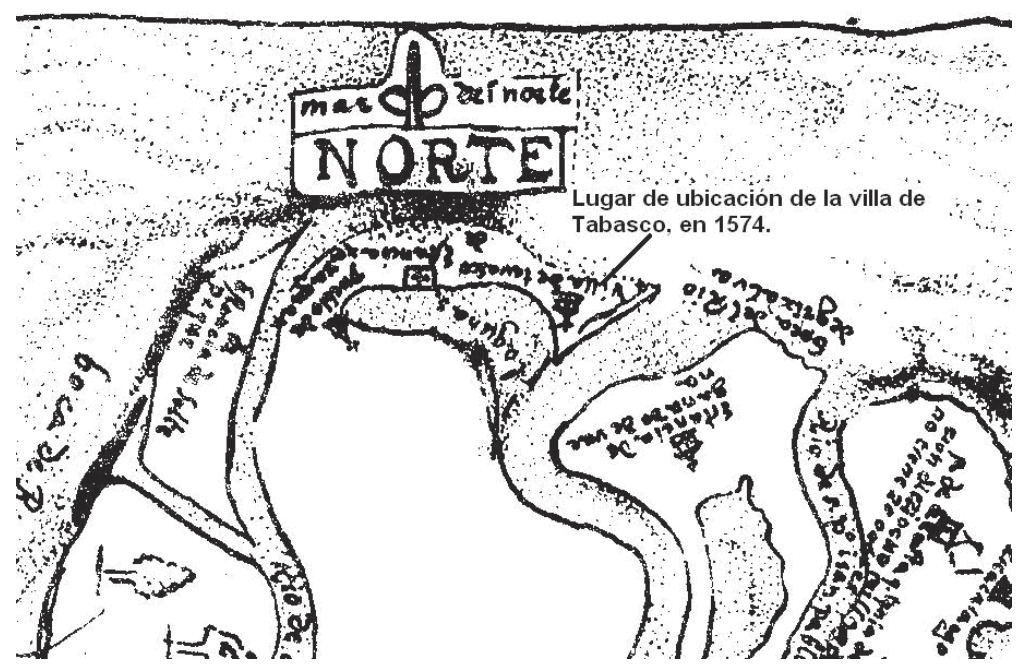

Figura 2. Mapa de la Provincia de Tabasco, por Melchor Alfaro de Santacruz, 1570. Detalle de la Barra de Frontera. Paleografiado y editado por F. J. Santamaría en 1917. Sin escala. Dibujo de Emilio Pérez Siliceo

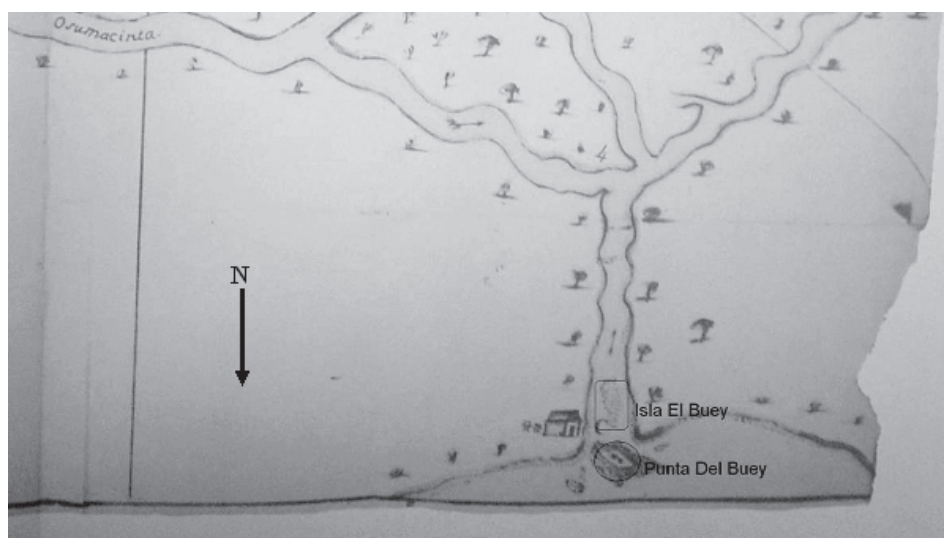

Figura 3. Detalle de un mapa que comprende desde Villahermosa hasta la Barra Principal DE TABASCO. Dibujado por Antonio Ballester, posiblemente hacia 1675. Escala gráfica en leguas españolas. En el mapa se aprecia cómo la isla El Buey no es sino un área azolvada del río, que sin ser una isla, pudo encontrarse como los "arenales" donde Cortés desembarcó en marzo de 1519 (Cortés, 1988: 15) 


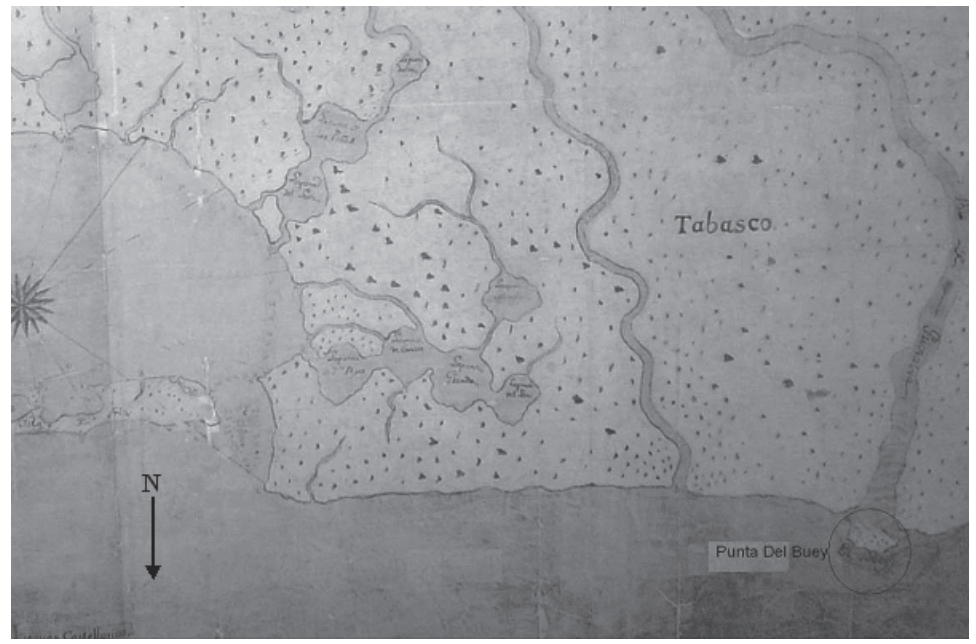

Figura 4. Plano de la Isla de Tris, donde se aprecia en detalle la Barra Principal de Frontera. Anónimo. Dibujado probablemente hacia 1750. Escala gráfica en leguas castellanas

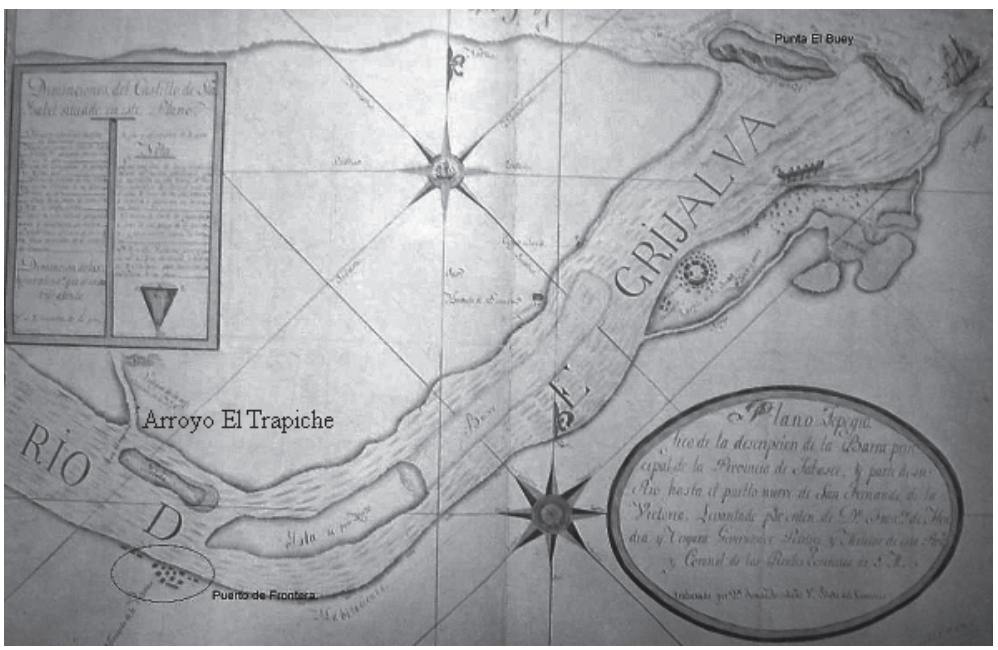

Figura 5. Plano topográfico de la descripción de la Barra Principal de la Provincia de Tabasco, con su pueblo nuevo de San Fernando de la Victoria. Sin fecha (probablemente de 1805, principio del siglo xix). Levantado por orden de don Francisco de Heredia y Vergara, y trabajado por don Tomás Avedaño, primer piloto del comercio. Escala métrica en varas castellanas 


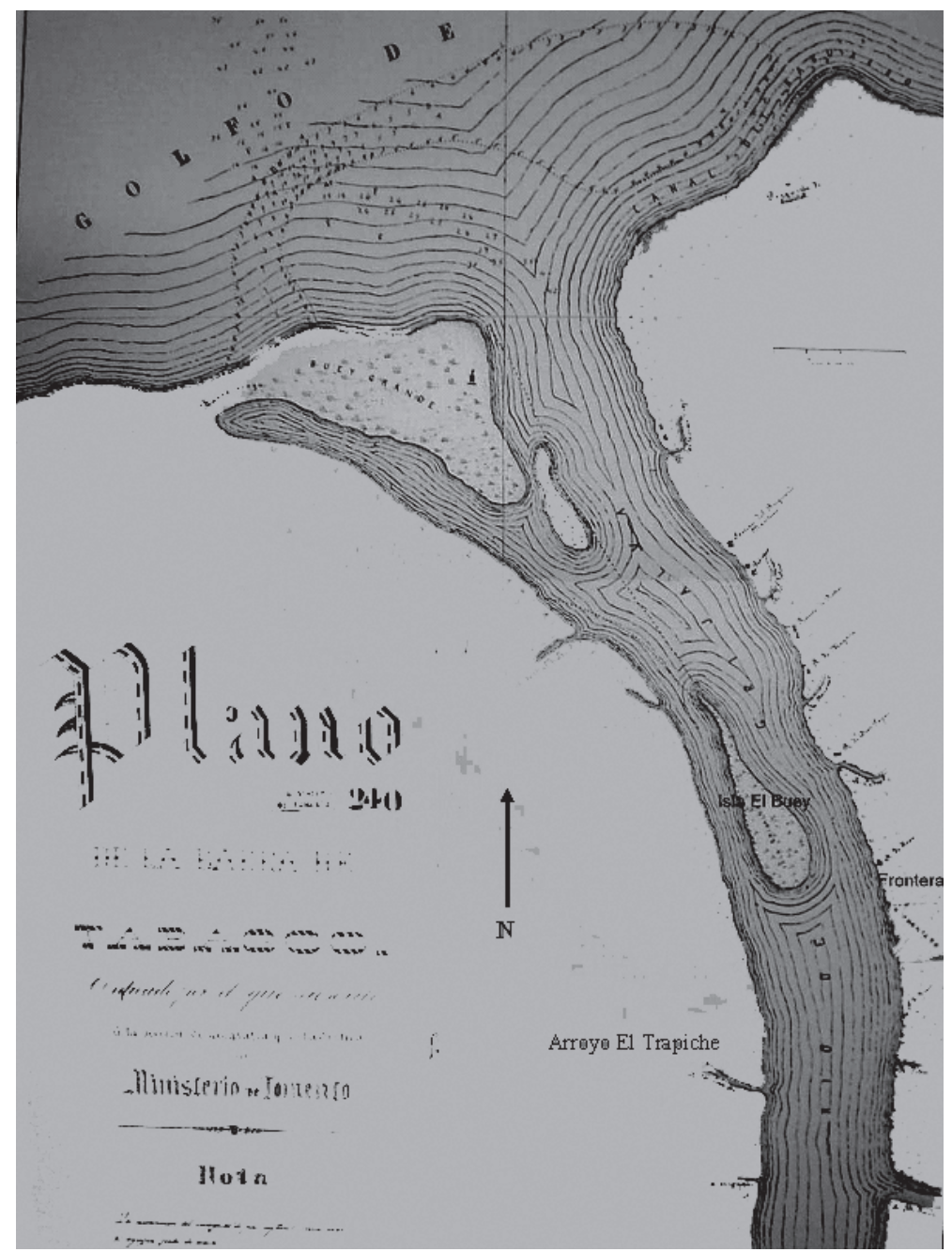

Figura 6. Plano de la Barra de Tabasco, por José Dolores Payán. Marzo de 1861. Donde se muestra la dirección y la dinámica de la corriente marina en la Barra y el interior del río Grijalva. También se pueden apreciar las áreas de arenales y las costas bajas. Se cuenta además con la numeración de sondeo en pies ingleses, donde $A$ significa fondo de Arena, y $F$ fondo de Fango 


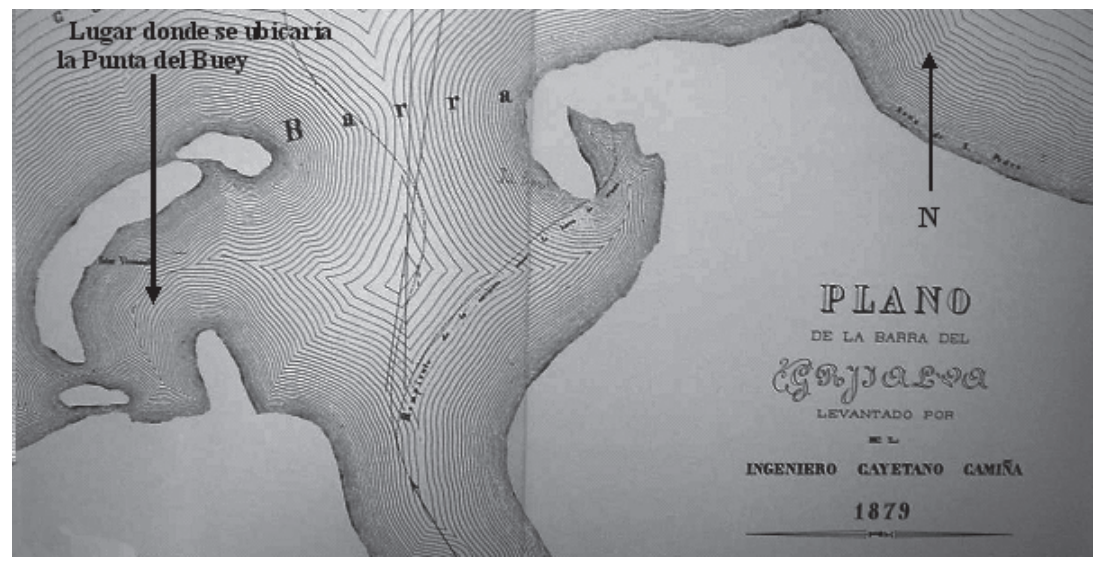

Figura 7. Plano levantado por el ingeniero Cayetano Camiña y dibujado por F. Navarro, 1879. El mapa tiene marcado el rompiente de la corriente cuando se cruza la Barra

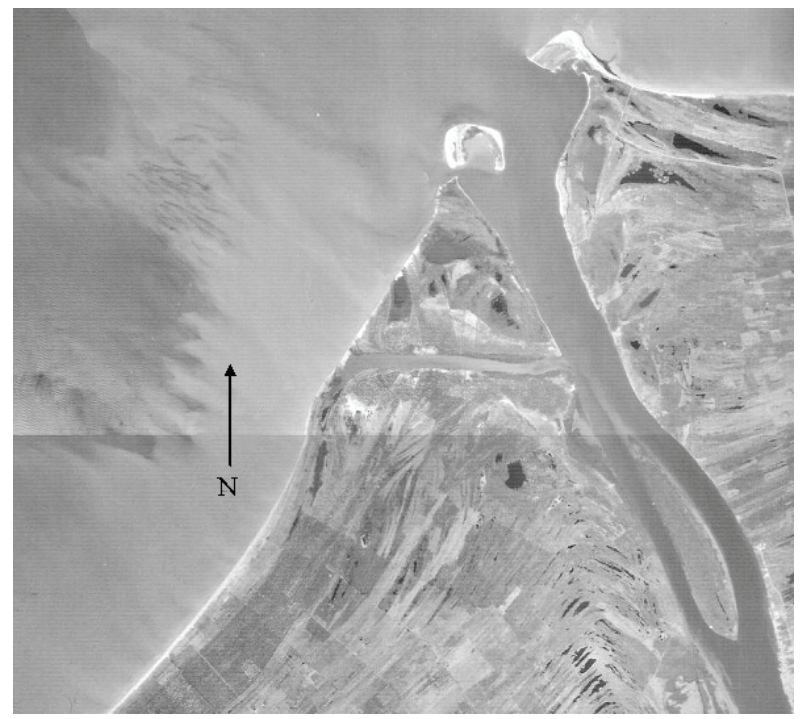

Figura 8. Fotografía aérea del Área próxima a la desembocadura del río Grijalva, desde donde se aprecia la Isla del Buey y la Barra Principal de Frontera, escala 1: 50000. INEGI, 2000 


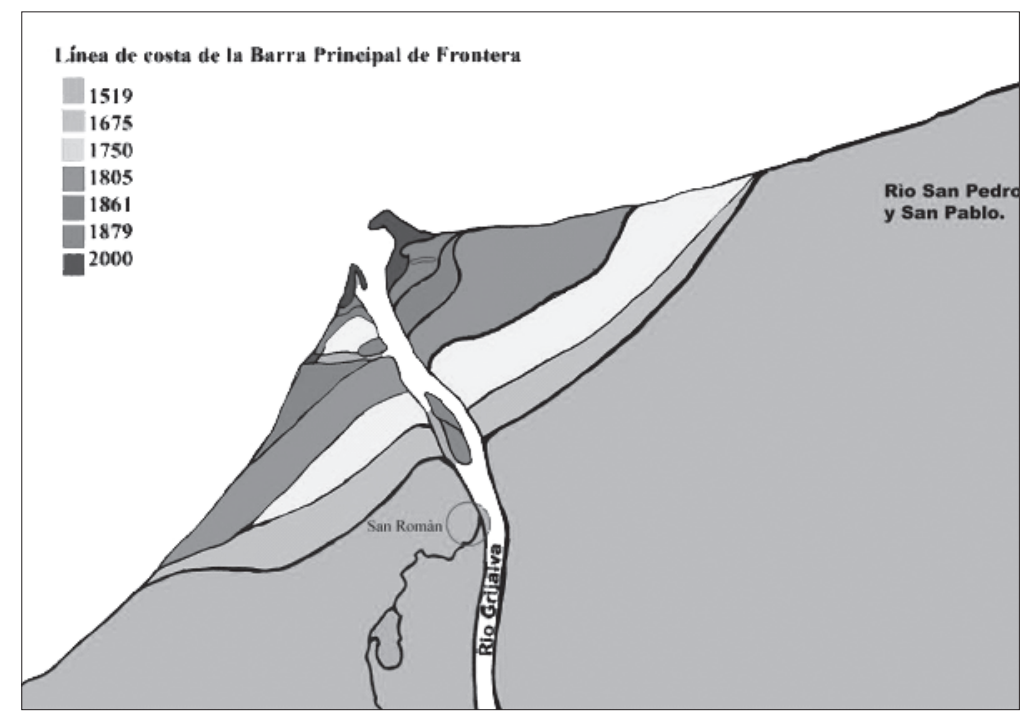

Figura. 9. Propuesta de modelo geomorfológico sobre la eVolución del delta del Grijalva, y el área de terreno ganado al mar desde 1519 a la fecha Elaboración del autor

\section{Antecedentes históricos de la región}

Bien puede considerarse que el Golfo de México y las tierras adyacentes a lo largo de la costa de la península de Yucatán y del Mar Caribe formaban una unidad económica en la época de la conquista. Aunque toda esta área contenía gran número de pequeños estados independientes, se unían en su totalidad a través de relaciones comerciales que constituían el vínculo de interés común. La economía comercial durante el Posclásico incluía una basta red de transporte, mercados, comerciantes y mercaderes, quienes en su conjunto mantenían sólidas relaciones económicas, gracias a sus relaciones políticas, con diversas regiones a través de Mesoamérica (Gasco y Berdan, 2003: 110-111). Las relaciones políticas, a su vez, se veían favorecidas por alianzas o relaciones de parentesco entre diversos caciques. Incluso, las incursiones bélicas podían verse suscitadas por el control de áreas de recursos o rutas comerciales; por ejemplo, el cacique de Potonchán, en Tabasco, era hermano del cacique de Champotón, en Campeche (Díaz del Castillo, 1970: 59). Potonchán y Champotón, junto con Xicalango y Tabasquillo habían declarado la guerra a Tixel, el cual se despobló para fundar Mactun, "que llaman Acalan" (Scholes y Roys, 1996: 315). Este fenómeno de alianzas y batallas entre estados pudo haberles traído ventajas económicas a todos los participantes en estas guerras, pero en el caso de Champotón y Poton- 
chán, su ganancia en los conflictos bélicos pudo traducirse en el control de las áreas de distribución de productos específicos que se comerciaban en diversas regiones. De esta manera, Tabasco exportaba por todo Mesoamérica plumas de aves exóticas de la región. Junto con Honduras, Tabasco también mantenía el control de la producción de cacao en el área maya. Una de las rutas de control pudo librarse, tal vez, a través del camino del río Grijalva a la depresión central de Chiapas hasta Quechula, de donde partían dos caminos: uno hacia Tecpatan, al oeste, y otro hacia el Soconusco y Anahuac Ayotlan, al este (Ortiz, 1988: 31). Ya en el Soconusco, esta ruta se podía entroncar con la ruta transítsmica a Centroamérica, especialmente hacia la provincia Pipil de Cuscatlan, en El Salvador (Fowler, 1989: 275). Chikinchel, en Yucatán, tenía la cuasi-equivalencia a un monopolio en la producción "industrial" de sal (Masson, 2001: 353), especializándose también en exportar a sus vecinos ropa de algodón y esclavos. Comerciantes de Xicalango y Potonchán, en Tabasco, y de Champotón y Campeche, al sudoeste de Yucatán, tenían depósitos y factorías en Honduras, en las márgenes del río Ulúa (Scholes y Roys, 1996: 16).

A nivel histórico, el sitio más importante durante el Posclásico en las costas de Tabasco era Potonchán. Esta ciudad fue la capital de la provincia de Tabasco, y se localizaba sobre la margen oeste del río Grijalva. Fue descrita por Hernán Cortés (1963: 12) y Bernal Díaz del Castillo (1970: 50) como un gran puerto marítimo que comerciaba con productos provenientes de muchísimos lugares a lo largo y ancho de Mesoamérica (figura 10). Al parecer, la prosperidad de Tabasco se debió a su gran capacidad comercial sobre un vasto territorio geográfico (Cabrera y Vargas, 1985: 10-13), y a la gran producción anual de cacao, cuyo fruto crece durante todo el año (Scholes y Roys, 1996: 32). Potonchán también impor-

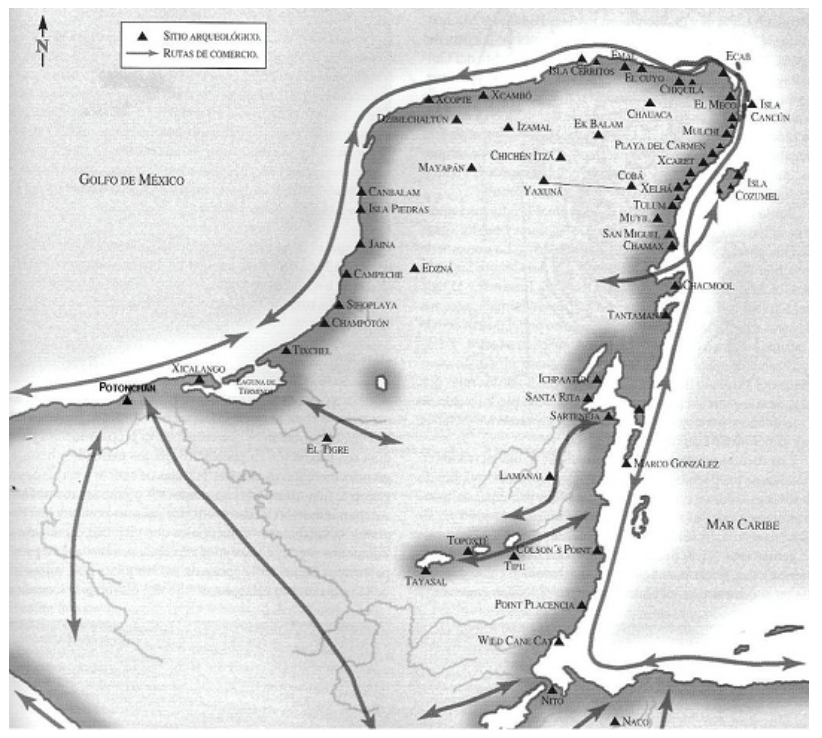

Figura 10. MAPA DE LAS RUTAS DE COMERCIO MARÍTIMO en el área maya para la época de la Conquista Tomado y modificado de Andrews, 1998 
taba productos como el oro y chalchihuites desde el lugar "donde se pone el sol, y decían Culúa y México" (Díaz del Castillo, 1970: 59), así como obsidiana verde proveniente de Sierra de las Navajas, en Hidalgo, cuyos productos elaborados, como navajillas de obsidiana, han sido recuperados arqueológicamente en San Román. El comercio entre los chontales era tal, que la isla de Cozumel, siendo famosa en la época de la conquista por el adoratorio de Ix Chel, la diosa de la luna, era visitada entonces por peregrinos que venían desde Potonchán y Xicalango (Scholes y Roys, 1996: 71).

Thompson (2004: 22) afirmaba que los grupos putunes (o chontales) provenientes de Potonchán, hubieron de controlar el área donde el río de la Pasión y el Chixoy se unen para formar el río Usumacinta, manteniendo una base comercial en el sitio de Altar de Sacrificios, para su Fase Terminal, y controlando todo el comercio para el Posclásico Tardío por todo el Usumacinta (Thompson, 2004: 25). Se sabe además que los chontales de Tabasco habían sido afectados por "la cultura mexicana" (Scholes y Roys, 1996: 28), en un área donde por lo menos había ocho o quizá más ciudades de habla nahua. Andrews (1998: 16), citando a Thompson, consideró a los mayas como los "fenicios de Mesoamérica", afirmación que tiene mucho de cierta, ya que las investigaciones realizadas en los últimos 20 años han revelado una compleja estructura asociada al comercio y la navegación, tanto marítima como fluvial. Potonchán, de acuerdo con los criterios de este autor, debió de ser tanto 1) un puerto comercial, como 2) un puerto de paso para el comercio de larga distancia. Ambas categorías están relacionadas con la función que Potonchán tuvo como puerto costero importante, en relación con las rutas comerciales con otros puertos costeros de la Península; y con la referencia de Potonchán como puerto que vinculaba las rutas comerciales marítimas y las rutas comerciales fluviales a larga distancia tierra adentro, con otros sitios en tierras altas. Andrews (1998: 20) afirma que el río Grijalva debió de ser uno de los ríos más importantes a través del cual se transportaba gran parte del volumen de comercio maya. Por ello es natural pensar que la importancia del área de Frontera como puerto y enclave comercial, debió de haber sido crucial y vital para toda la red de comercio marítimo y fluvial que se distribuía a lo largo del área maya.

En 1519, en uno de los fenómenos sociales más dramáticos que habrían de suceder en el área, Hernán Cortés bordeaba la costa desde la península de Yucatán, siguiendo las rutas comerciales marítimas mayas, y llegó a Tabasco frente a la boca del río Grijalva, donde atracaría para tiempo después internarse en la ciudad de Potonchán el día 12 de marzo de $1519^{2}$ (Gil y Sáenz, 1979: 37-40). Según las fuentes históricas, el poderío de Potonchán en la región era tal, que

\footnotetext{
${ }^{2}$ Existe un problema cronológico en el que varios autores pasan el día de la llegada del 12 hasta el 21 de marzo, esto, supongo, es causado por el cambio y adopción real a fines de la década de 1590 del calendario juliano por el calendario gregoriano, que desfasaría el año en aproximadamente 10 días.
} 
pudo convocar grandes cantidades de soldados para defender la capital chontal de los invasores hispanos. Díaz del Castillo dice que fueron aproximadamente 12000 guerreros venidos de varias provincias lejanas, llamados a la batalla por el cacique de Potonchán, Taabs Coob (Díaz del Castillo, 1970: 54-56). En la actualidad, varios autores estiman cantidades de 10000 hasta 13000 guerreros (Izquierdo, 1997: 178), llegando incluso hasta los 40000 guerreros (López Reyes, 1979: 19). Una vez ganada la batalla en Potonchán y las llanuras de Centla, los españoles recogieron a sus muertos y heridos y se dirigieron a su Real, liberando a todos los cautivos indígenas y dándoles la orden de mandar traer a sus principales, pues querían entrar en pláticas con los caciques para que se hiciera la paz en la región. Un día después llegaron representantes de Potonchán y otras entidades para entrar en pláticas y dar presentes, Cortés aceptó los presentes en especie así como 20 mujeres, entre las que iba la Malinche, su posterior mejor arma de conquista.

Y después de apeados y debajo de unos árboles y unas casas que ahí estaban, dimos muchas gracias a Dios por habernos dado aquella victoria tan cumplida; y como era un día de Nuestra Señora de Marzo llamóse una Villa que se pobló, el tiempo andado, Santa María de la Victoria (Bernal Díaz, 1970: 55).

El sistema comercial marítimo maya fue entonces reutilizado por los españoles para transportarse hacia todas las nuevas colonias fundadas a lo largo del Golfo de México, la península de Yucatán y El Caribe. Tabasco tuvo además, una importancia estratégica dadas las diversas campañas de conquista hacia la península de Yucatán y Guatemala (por los caminos de tierra adentro), desde 1525 hacia mediados de 1550 (Jones, 1998: 41) (figura 13). En enero de 1524 llegó a Tabasco Juan de Vallecillo como capitán general de la provincia de Tabasco, con 60 soldados españoles (Relaciones histórico-geográficas..., 1981: 425), y 200 indígenas aztecas y tlaxcaltecas, estableciéndose en el lugar donde Cortés había dictaminado la creación de una Villa cinco años atrás, con la intención de fomentar un comercio marítimo entre Veracruz y Campeche, fundándose así la Villa de Santa María de la Victoria. En dicha ruta portuaria, los barcos debían salir desde Veracruz y pasar por Tabasco hacia la península de Yucatán, y luego España. Santa María de la Victoria se convirtió con el tiempo en un asentamiento de desarrollo urbano complejo (Salazar y Chávez, 2005: 84), y adquirió así una importancia económica producto del comercio, como en cualquier otra villa española de las costas del Golfo y Yucatán.

Santa María de la Victoria fue una villa que, por su ubicación tan "penosa", hubo de sufrir el asedio pirata ya desde principios de $1570 .^{3}$ En 1557 comenzaron a registrarse las incursiones de corsarios y piratas ingleses en las costas de

\footnotetext{
${ }^{3}$ El Cabildo de la Villa de Santa María de la Victoria escribió en 1579 que: "habrá ocho o nueve años estuvo en este río (Grijalva) un navío de ingleses corsarios” (Relaciones... 1981: 423). Donde los
} 
Tabasco tras su apoderamiento de la isla del Carmen. Esto orilló a un grupo de españoles acaudalados e indígenas de Santa María de la Victoria a dirigirse río arriba del Grijalva, asentándose en Villa Carmona (que posteriormente habría de convertirse en San Juan Bautista), lo que provocó una fragmentación en los intereses de los distintos sectores involucrados, básicamente la propiedad de encomiendas cerca de la costa donde se mantenían grandes zonas ganaderas y agrícolas.

Los ataques piratas fueron tan concisos y fuertes que en 1597 casi se apoderan de Campeche, siendo repelidos por los soldados españoles. Ese mismo año los piratas por primera vez lograron tomar Santa María de la Victoria, quemándola por completo y secuestrando además a mucha gente. El gobierno respondió trasladando los poderes a Tacotalpa (López, 1979: 64-67; Rovirosa, 1946: 10) ya que los piratas habían incluso atacado San Juan Bautista, y destruido la primera edificación de ladrillo, El fortín de la Loma, que resguardaba los intereses reales. Por esta época el pueblo de Atasta y Tamulte de la Barranca se trasladaron tierra adentro.

Tras la huida de los piratas, los pobladores reconstruyeron su iglesia y nombraron un nuevo cabildo y oficiales reales para perpetuar el nombre del primer poblado fundado en México. No paso mucho tiempo hasta que el alcalde abandona la Victoria y se dirige a la Villa Hermosa de San Juan Bautista juntando a toda la población para poner a voto la petición del traslado de los poderes a dicha ciudad y comenzar el proceso para abandonar el asentamiento costero:

y por faltarles las comodidades de vivir hicieron una casa en el campo, muy lejos de la dicha villa (la Victoria) el río arriba, donde se registran las mercaderías a voluntad de los dueños... Sería bien mudar y pasar la dicha villa junto a la dicha casa, por ser parte acomodada para la vivienda y contratación de los dichos vecinos, entrando y saliendo por tierra y con esto vendríanse a excusar el peligro en que siempre habían estado, de ser robados y saqueados de corsarios enemigos que allá suelen llegar (Izquierdo, 1995: 35).

Desde 1570 y hasta finales de 1619 la situación en la Victoria y en terrenos cercanos habría de empeorar debido a una baja demográfica significativa en los alrededores del río Grijalva, cuando fueron abandonados tres pueblos cercanos a la Victoria, para comenzar el poblamiento de otras áreas más seguras. En 1603 el alcalde Mayor de Tabasco pide al virrey el traslado de la capital de los poderes en Tabasco de la Victoria a San Juan Bautista (Izquierdo, 1995: 26). Finalmente no fue sino hasta 1641 cuando se hizo el traslado oficial de la capital de Tabasco tierra adentro, a San Juan Bautista. El área del delta del Grijalva sufrió entonces un proceso de abandono gradual que bien pudo tomar varios años en suscitarse completamente.

piratas sondearon los puertos de la costa, tomando leña y agua; tiempo durante el cual, los habitantes de la Victoria vivieron una época de "mucho aprieto", por custodiar la villa y playa, sin ninguna fuerza para resistir algún embate. 


\section{Antecedentes arqueológicos del sitio}

El desarrollo de investigaciones arqueológicas en la región costera de Tabasco fue durante la década de los cincuenta, bastante prolífico. Desgraciadamente en tiempos más recientes, éste se ha visto casi nulo. Si bien el interés de los especialistas en la región es grande, ya que en esta área se localizan los restos arqueológicos de la primera población indígena mencionada por los españoles en el siglo xvı, y la primera capital en Tabasco, los trabajos que dan cuenta de una secuencia arqueológica para la región costera de Centla, en Frontera, son prácticamente inexistentes.

Ya hacia mediados del siglo xix Richard Berendt excavó en la región de Frontera, ${ }^{4}$ cerca de la desembocadura del Grijalva. Su trabajo sirvió de referencia obligada para todos aquellos interesados en estudiar la arqueología de la región costera de Tabasco. Desafortunadamente dicho trabajo no ha podido ser consultado por quien escribe aquí, debido a la antigüiedad del texto. Daniel Brinton en 1899 es quien menciona los trabajos de Berendt. Uno de los primeros trabajos de orden histórico, donde se hace énfasis en la necesidad de intervenir arqueológicamente, es el trabajo de don José Ugalde (1916), quien le presenta a don Manuel Gamio un "Informe de la localización de la zona arqueológica de Cintla, Tabasco". Este trabajo forma parte de una serie de informes que sirvieron para dar cuenta de los sitios arqueológicos mencionados por Hernán Cortés y Bernal Díaz del Castillo. Menciona las excavaciones hechas en 1869 por Berendt, pero no ahonda en sus resultados. Básicamente este trabajo se propuso hacer una descripción histórica de la problemática arqueológica. Ofrece además una justificación sobre la importancia de los trabajos hechos por Berendt, y la continuidad de su validez científica. En 1919 Ugalde presenta otro informe sobre la historia de "Tabasco desde el período prehispánico, colonial y del México independiente”. En su apartado sobre monumentos históricos menciona varios lugares en Villahermosa, y comienza a cuestionarse sobre la posible localización de Santa María de la Victoria.

En 1925 Franz Blom realizó su expedición a la "América Media”, a través de la universidad de Tulane en Louisiana, navegando por toda la costa del Golfo de México, hasta Tabasco, donde pasa por la Barra de Tupilco, Dos Bocas, y se mete por la boca del río Grijalva, desembarcando en Frontera (Blom, 1926: 97, 98) (figura 11). Aunque Blom no hizo ningún tipo de trabajo de campo, sí hizo un recuento del trabajo hecho por Berendt, citado por Brinton. También menciona los trabajos hechos por Charnay, quien visitó varios sitios cerca a La Bellota, al sur del rancho El Coco, y describió pirámides con acabados en mampostería a base de ladrillo cocido, a la manera de Comalcalco. Visitó a quien en ese momento fue el guardabosques del área, y éste le mostró gran cantidad de objetos reco-

\footnotetext{
${ }^{4}$ Esta región puede también entenderse como la totalidad del área que comprende el delta del Grijalva.
} 
lectados, entre los que destacaron los cascabeles de cobre, los cuales, dada su abundancia, hicieron suponer a Blom que pudieron venir por comercio con grupos nahuas o toltecas.

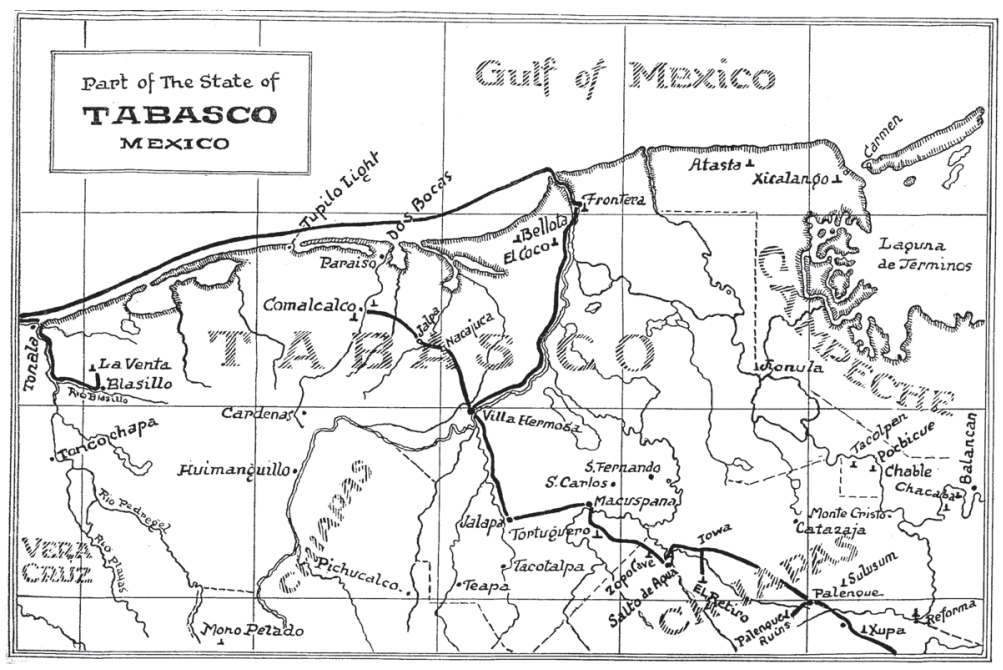

Figura 11. Ruta SEguida POR Blom en su viaje desde Veracruz, por Frontera Tabasco y hasta Chiapas, en 1925

En 1956 Heinrich Berlin excavó en diversos lugares en Tabasco. Uno de ellos es el sitio que llamó Juárez (figura 12), y que identificó como el Cuyo Grande, sitio excavado por Berendt en 1869. Describe arquitectura de ladrillo observada desde la superficie, y cerca del montículo principal. Reporta además ladrillos como muro de contención de una terraza. El grosor del muro lo estima en 1 metro aproximadamente. El piso estaba constituido por una capa de sascab, cuyo grosor no pudo determinar. Al parecer, dicha estructura y su terraza corresponden a una etapa constructiva posterior al resto de sitio. Afirma que aunque Tabasco ha sido poco explorado arqueológicamente, las construcciones de ladrillo y mortero que aparentemente son indicadores de etnicidad entre los chontales, aparecen a lo largo de la costa del estado. Identifica el horizonte "Cintla", definido por cerámica proveniente de Tamulté, Juárez y Atasta. El horizonte "Cintla" es un período protohistórico, que cubre 200 años previos a la llegada de los españoles.
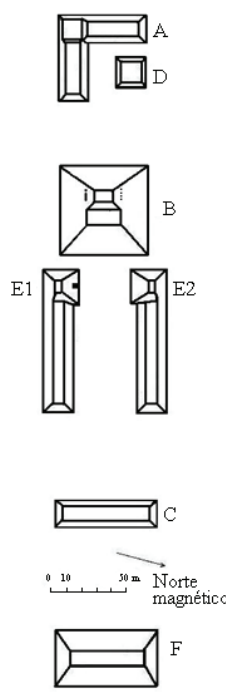

Figura 12. Sitio de Juárez, identificado por Berlin como el Cuyo Grande de Berendt Tomado de Berlin, 1956 
Describió los sistemas constructivos de las estructuras a base de ladrillo, apisonados de tierra y sascab. Reportó también cerámica del horizonte Cintla, en su mayoría anaranjado fino de los tipo $V$ (Matillas) y $U$ (Cunduacan). Afirmó que la arqueología de la región del bajo Grijalva se mantiene más o menos uniforme en cuanto a indicadores arqueológicos se refiere (sistemas constructivos, materiales cerámicos, líticos, etc.). No localizó ocupaciones anteriores, del Preclásico o Clásico Temprano. Esto lo llevó a afirmar que la ocupación de toda el área debió de llevarse a cabo en su mayoría durante el Posclásico Tardío. Sin embargo, por analogía con otros sitios de la región costera, estudia la posibilidad de que haya habido ocupaciones tempranas (Laguna de Términos, La Venta, y cerca de Comalcalco. Todas estas ocupaciones están ligadas al Preclásico Olmeca). Menciona además, que Edward Seler excavó en 1912 un basurero cercano del sitio de Juárez, en Tabasco, y localizó materiales del horizonte denominado Jonuta, que abarca el Preclásico y parte de Clásico Temprano. Parte de su trabajo también la dedica a revisar el trabajo de Berendt, citado por Brinton en 1896. Estudia el caso de la Cintla donde Cortés entabla su primera batalla en territorio tabasqueño, y de la identificación arqueológica del sitio histórico que realiza Berendt. Difiere de la opinión de Berendt, a partir del supuesto de que cualquier sitio con arquitectura localizado sobre el margen oeste, cercano a la desembocadura del Grijalva, es potencialmente la Cintla e incluso el Potonchán que mencionan las fuentes históricas. Berlin critica que después del trabajo de Berendt toda la comunidad académica de la época estuvo de acuerdo en las conclusiones a las que llegó. Sin embargo, enfatiza que pocos estudiosos pusieron atención al hecho de que Berendt nombra toda la cerámica obtenida de la región como cerámica proveniente de Centla; Centla como región fisiográfica y no como sitio arqueológico específico, por lo que la cerámica obtenida durante su intervención no puede ser tomada como proveniente de un sitio arqueológico, sino de muchos sitios cercanos (figura 13).

Esto permite a Berlin abrir la polémica en torno a la localización de Cintla y Potonchán de nuevo, al negar la identificación hecha por Berendt. Su estudio lo concluye argumentando que incluso la Villa de Tabasco (Santa María de la Victoria) - que tuvo materiales aún más diagnósticos en términos de etnicidad y temporalidad, los cuales podrían ayudar a facilitar su identificación- no había podido ser localizada hasta esa fecha.

Por otro lado, Florencia Müller, durante la década de los años sesenta realizó el Atlas arqueológico de Tabasco (Müller, 1967). En él se mencionan de nuevo los trabajos de Berendt en la región costera del Tabasco, pero no los de Berlin. Propone que la filiación étnica de la región debió de ser Maya-Nahua, utilizando la periodificación dada por Berlin, aunque añade a la fase Cintla un período denominado Cocom Xiu, donde hay una fuerte penetración de grupos nahuas a la región. Describe además los mismos sistemas constructivos a base de montículos de tierra aplanada y terrazas recubiertas con sascab. Accesos y esquinas a base de ladrillo cocido. 


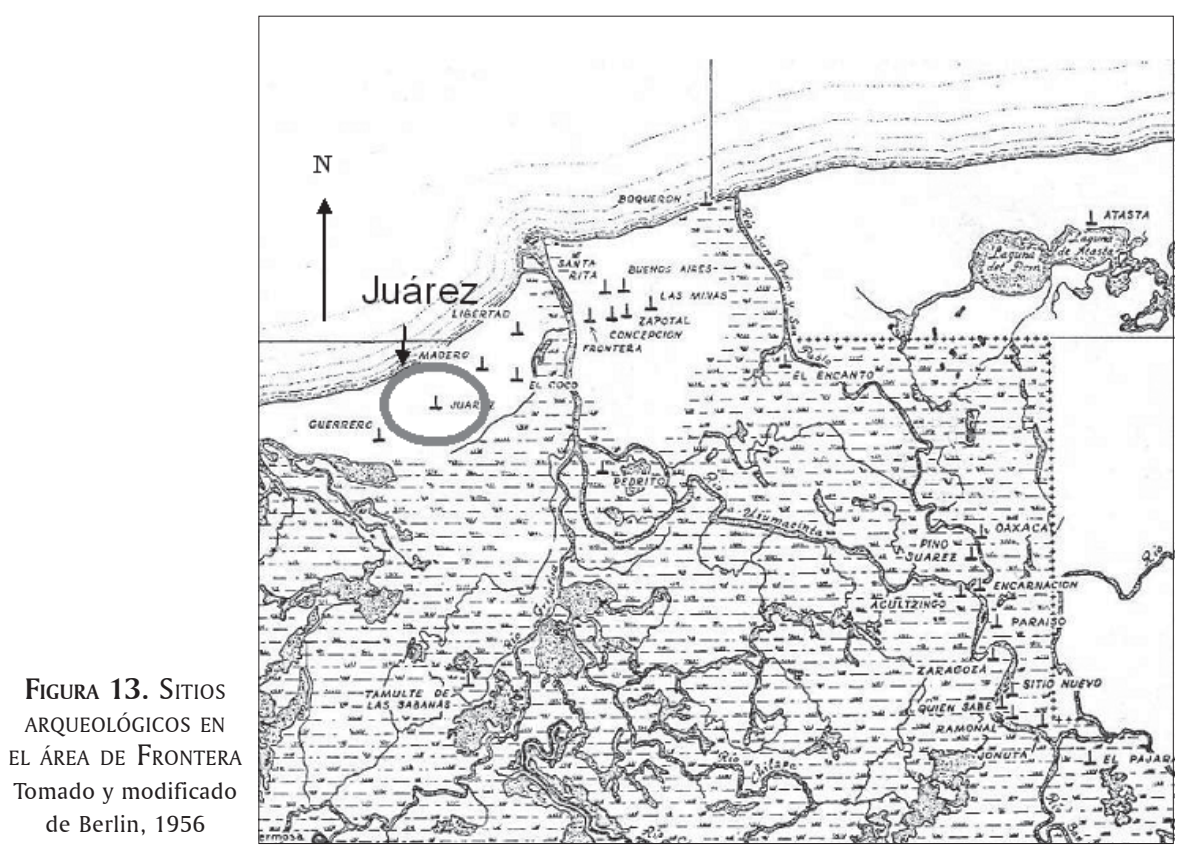

Spinden $(1975: 195,196)$ remitió al estudio de Brinton y Berendt para hablar de materiales arqueológicos recuperados en "las ya muy llamadas ruinas de Cintla", consistentes en figurillas antropomórfas de guerreros. Además sugiere que la tradición de incensarios de pasta burda y antropomórfos, tan comunes en todo el Golfo de México y Yucatán, pudieron tener un origen tabasqueño, asociado al área que cubrieron las ruinas de Cintla (Spinden, 1975: 196).

Gaxiola y Ramírez (Fernández et al., 1988: 34), retomando el trabajo de Ugalde (1916), ilustraron la descripción de Cintla con imágenes obtenidas del trabajo de Chavero (1940: 166, 167), refiriéndose a la Cintla tabasqueña. Sin embargo, Chavero se refiere en su libro más bien a una Cintla ubicada cerca de Cofre de Perote y del Pico de Orizaba, en Veracruz, por lo que su identificación entre las imágenes utilzadas y la descripción de Cintla por Ugalde, no corresponde en lo absoluto.

Ernesto Vargas (2001: 44-45) sugirió que uno de dos sitios cercanos al Grijalva por su margen oeste podrían corresponder con el Potonchán histórico, éstos son el Sitio de El Pájaro y Allende, ubicados tierra adentro. Su argumento principal descansa en los trabajos de reconocimiento hechos por él, donde ningún otro sitio cercano a la desembocadura del Grijalva corresponde en tamaño e importancia, por los restos arqueológicos, con el sitio descrito por las fuentes, a excepción tal vez de estos dos sitios. También hace referencia a Los Ídolos y San Román como sitios alguna vez identificados por Thompson como el Potonchán histórico, pero que debido al tamaño fueron descartados como dicho sitio histórico (Vargas, 2001: 45), el primero de estos sitios está localizado en lo que 
actualmente es la cabecera municipal del Centla, Frontera; y el segundo, localizado frente a ésta, y de donde proviene el material cerámico analizado en esta investigación.

En otras ocasiones (Chávez, 2002 y 2005) he venido sugiriendo que la arqueología del delta del Grijalva no podría ser entendida de no ser explicada en relación con la transformación gradual y constante del terreno, en un proceso donde la tierra le ha venido ganando terreno al mar, transformando por completo la geografía del área, y difiriendo del terreno del siglo xvı. Lo que se traduce en la no correspondencia entre fuentes cartográficas históricas, y la geografía actual. Un análisis de las fuentes históricas, tomando en cuenta el fenómeno geomorfológico de transformación del terreno en el delta del Grijalva, me llevó a sugerir que el sitio San Román (del cual el área excavada forma tan sólo una pequeña parte) y el sitio de Frontera conforman una misma unidad sociopolítica, que podría corresponder con el Potonchán histórico. En el caso de la Villa de la Victoria, ésta se podría encontrar localizada en parte del mismo asentamiento de Potonchán, sobre el cauce del arroyo El Trapiche, antes de entrar a la laguna El Coco, en un área donde de acuerdo con los lugareños, como ellos la nombran, se encuentra la "Isla de los Tepalcates"5 (Chávez, 2005), la cual no está compuesta por tepalcates pertenecientes a piezas cerámicas, sino a ladrillos de arcilla que parecen conformar un muro, tal vez de contención, en un área donde en estas fechas no se registra ninguna actividad humana capaz de explicar su posición en la actualidad. Dichos ladrillos, en una observación personal, distan mucho del típico ladrillo prehispánico descrito por Berlin, como: ladrillos relativamente delgados, cuyo color va del rojo, café al gris, los cuales aparecieron en las estructuras del Clásico en Comalcalco y Bellote, y fueron utilizados hasta los tiempos de la conquista (Berlin, 1956: 102, la traducción es mía); en cambio, los ladrillos de la "Isla de los Tepalcates" son rectangulares con un grosor muy proporcional a su largo y altura, lo que los hace casi cuadrangulares, y distintos además de los ladrillos rectangulares actuales. De cualquier manera, sólo una serie de excavaciones arqueológicas en este lugar podrán esclarecer su origen temporal.

Después de los últimos trabajos de Berlin, la región de Frontera ha sido estudiada por arqueólogos e historiadores desde los libros, lo que ha originado una prolífica discusión con respecto a la arqueología del área, pero que no ha contribuido con ninguna evidencia arqueológica a la discusión (Izquierdo, 1997 y 2005). Existen además, análisis históricos que emiten hipótesis para la localización de los sitios históricos en la geografía del área de Frontera en la actualidad (Salazar y Chávez, 2005; Chávez, 2002, 2005; Izquierdo, 1997: 171-182 y 2005).

\footnotetext{
${ }^{5}$ En 2003 la antropóloga Flora Salazar Ledesma y el autor, realizamos un reconocimiento del área del arroyo El Trapiche hasta la laguna El Coco. Dicho reconocimiento trajo como resultado la identificación de lo que fue un muro de ladrillos, ahora colapsado, sobre la margen del arroyo, que pudo ser, a mi criterio, de manufactura temprana en el área, en tiempos históricos.
} 
Sin embargo, todos los trabajos hasta la fecha han sido de carácter especulativo; que aunque válida y necesaria, la especulación por sí misma se ve rebasada por los primeros resultados arqueológicos concretos en casi 50 años. El estudio cerámico realizado en un tesis de licenciatura (Chávez, 2006) aportó la secuencia cerámica del área, necesaria para abordar cualquier problemática arqueológica que sea propuesta y realizada para la región. De esta manera, se espera contribuir con evidencia sólida que servirá de punto de partida para la continuación del quehacer arqueológico en la arqueología de la región de Frontera.

\section{¿Dónde están Potonchán y Santa María de la Victoria? Una propuesta histórico-arqueológica}

Durante años, gracias a las fuentes históricas, se ha podido, en diversos lugares del mundo, encontrar arqueológicamente sitios cuya ubicación ha sido ya un viejo problema para las personas que los estudian, o se relacionan con ellos. En este trabajo se ha planteado la problemática alrededor de la identificación y ubicación de Potonchán y Santa María de la Victoria utilizando el contenido de las fuentes históricas como referente inmediato a los indicadores arqueológicos, cuya contrastación en la actualidad se podrá resolver con base en la interdisciplinariedad entre arqueología, historia y geomorfología, tomando en cuenta que las fuentes de primera mano fueron escritas gracias al conocimiento de una geografía dinámica que se puede rastrear en la actualidad.

Dice Díaz del Castillo:

En doce días del mes de marzo de 1519 años, llegamos con toda la armada al río de Grijalva, que se dice Tabasco, y como sabíamos ya que en aquel puerto y río no podían entrar navíos de mucho porte, surgieron en la mar los mayores y con los pequeños y los bateles fuimos todos los soldados a desembarcar a la punta de los palmares, como cuando con Grijalva que estaba del pueblo de Tabasco obra de media legua (2.2 km.) (Díaz del Castillo, 1970: 50).

La $\operatorname{leg} u a^{6}$ es una medida de distancia muy recurrente durante la Colonia. La legua es una medida itinerante de 20000 pies o 6666 yardas y 2 tercios, o 5577 metros y 70 centímetros. Pienso que el Potonchán que los españoles conocieron se localiza justamente a $2 \mathrm{~km}$. de la isla El Buey (la cual, debido a los cambios geográficos registrados a lo largo del tiempo en los mapas, a veces desaparece, otras se convierte en dos y hasta en tres islas separadas) y frente a la ciudad de Frontera. La idea de que dicha isla haya estado conectada por medio de una legua de tierra a la línea costera, como una bahía temporal, debido a la acumulación sedimentaria, no es para nada descabellada dadas las condiciones geomorfológicas

\footnotetext{
${ }^{6}$ Enciclopedia Universal Ilustrada, Espasa-Calpe, España, 1991.
} 
y ambientales antes discutidas. Asimismo Cortés (1963: 12) indicó que los españoles acamparon en unos "arenales" sin nunca especificar sobre qué margen del río desembarcaron, afirmó también que estaban rodeados por miles de indios "de hacer guerra" (Cortés, 1963: 12). Pienso que dadas las condiciones geomorfológicas del delta del Grijalva, estos arenales pudieron ser secciones azolvadas que emergían levemente del nivel del río, y que con los años habrían de transformarse en esta isla. Potonchán fue el primer sitio prehispánico al que llegó Cortes en Tabasco, y asimismo es el primer sitio ocupado por los españoles como campamento y descrito en su composición espacial por Bernal Díaz y Antonio de Solís. Al respecto, Bernal Díaz del Castillo escribió:

Y nunca volvieron de hecho las espaldas, hasta un gran patio donde estaban unos aposentos y salas grandes, y tenían tres casas de ídolos, y ya habían llevado todo en cuanto hato había. En los cúes de aquel patio mandó Cortés a que repasáramos y que no fuésemos más en seguimiento del alcance, pues iban huyendo [...] Cortés [...] Que desenvainada su espada, dio tres cuchilladas grandes en señal de posesión en un árbol grande que se dice ceiba, que estaba en la plaza de aquel gran patio [...] (Bernal Díaz del Castillo, en Cabrera Bernat, 1987: 39).

Antonio de Solís, quien siendo un conocedor de la historia en su época, afirma:

Aquella noche se alojó nuestro ejército en tres adoratorios que estaban dentro de la misma plaza donde sucedió el último combate y Hernán Cortes echó su ronda, y distribuyó centinelas, tan cuidadoso y desvelado como si estuviera en el frente de un ejército enemigo y veterano... (Antonio de Solís, 1999: 190).

En la margen izquierda del Grijalva se localiza el sitio arqueológico de San Román. Este sitio es de considerable tamaño y cuenta con 14 estructuras de tierra, de las cuales 13 son menores de 2 metros de alto y una está entre los 2 y 5 metros de altura. ${ }^{7}$ El arreglo espacial de este sitio es interesante, ya que el montículo de mayor tamaño se encuentra junto con otros montículos, formando un núcleo de montículos que cierran en una plaza, y cuya distribución corresponde con las descripciones históricas. San Román es el sitio de mayor número de estructuras en un radio de 10 kilómetros a la redonda. La extensión del sitio es otro elemento relevante, ya que a pesar de que el tamaño de este sitio es de .04 $\mathrm{km}(40 \mathrm{~m})$, en la margen izquierda del Grijalva, la ocupación arqueológica en la orilla occidental del río es de un sitio mucho mayor en tamaño (hasta donde el registro arqueológico verificó, el sitio mide $4 \mathrm{~km}$ de largo sobre la margen del río y de 200 a 300 metros tierra adentro), cuyo nombre es "Sitio Frontera". Toda la presencia de posibles restos de arquitectura prehispánica pudo ser destruida por la construcción y crecimiento de la actual cabecera del municipio de Centla, la ciudad de Frontera. A este sitio sólo se le puede encontrar una fuerte asocia-

${ }^{7}$ Registro Arqueológico, Carta INEGI E15B72: Carrillo Puerto. 
ción cerámica que cubre $2.5 \mathrm{~km}$. de longitud en la margen del río y que hace pensar en la existencia de un área ceremonial y habitacional separada por la barrera natural que presenta el río mismo, pero que no separa a dos sitios distintos, sino que es un solo sitio bien delimitado espacialmente por una barrera natural. Así, pienso que los dos sitios arqueológicos registrados en las dos márgenes del río Grijalva son en realidad un solo sitio prehispánico, y deberían ser considerados en la actualidad un solo sitio arqueológico.

Bernal Díaz es muy claro en las fuentes cuando afirma que después de ganado Potonchán y habiéndose nombrado la villa de la Victoria, ésta habría de poblarse varios años después en el mismo lugar (Bernal, 1970: 55). Sobre la villa de la Victoria dicen Vasco Rodríguez y Melchor Alfaro de Santa Cruz (1981: 416-417).

El río sobre que está fundada esta villa se dice río de Grijalva... Está este río y puerto en diecisiete grados y medio, obra de una legua de la boca del río sobre un placel de agua que se hace de la parte del norte, y sobre un brazo del río... Los barcos y barcas y fragatas que a esta villa vienen por carga o a descargar al pie de una cruz que es el remate de la calle de esta villa y loma en que está; surgen allí a causa de estar con el reparo de las casas abrigados del norte y vientos de la mar, que son los más dañosos y recios de esta costa.

Santa María de la Victoria fue la villa que habría de poblarse varios años después de la conquista de México, y era un asentamiento portuario-costero ubicado cerca de la desembocadura del río Grijalva en aquella época, donde:

Esta villa está fundada sobre una loma pequeña, menos de un cuarto de legua, de suerte que si no es la misma loma donde está dicho pueblo, todo lo demás es bajo y anegadizo, y por un lado sobre un brazo del dicho río que va hacia el pueblo de Taxagual, y por las espaldas está una ciénaga que cuando es tiempo de aguas se hincha y entra en los más de los solares que caen sobre la ciénaga, y en este tiempo casi no se pueden servir de los solares y corrales, ni salir de las dichas casas si no es por la calle principal, que no hay más calle de una en esta villa y es torcida conforme a lo que corre la dicha loma [...] Esta ciénaga viene ciñendo toda esta villa por las espaldas de ella y entra en un placel que hace sobre la iglesia de ella, y en todo es circuito de esta villa; no se ha hallado ni halla lugar cómodo para poder poblarse esta villa, porque cuando hay crecientes de los ríos todo se hincha y anega salvo el circuito; aunque está esta loma baja, a causa de que como es grande el río y la boca de él, espárcese el agua y sale sin dañar a esta villa, aunque con las dichas crecientes y pocos reparos que tiene por carecer de servicio va comiéndose y disminuyéndose esta loma [...] Hay en esta villa una iglesia en la cual asiste ordinariamente un sacerdote clérigo. (Vasco Rodríguez y Melchor Alfaro de Santa Cruz, 1981: 426).

Ya en otra ocasión se habló del asentamiento que pudo haber sido Santa María de la Victoria (Salazar y Chávez, 2005: 75-81), sin embargo, encuentro pertinente mencionar algunos indicadores arqueológicos para la identificación de la villa. Para tener una idea de a qué tipo de contexto arqueológico uno se puede 
enfrentar en campo, se deberá de descartar la arquitectura monumental, siendo que la iglesia y las casas tal vez se edificaron sobre plataformas pertenecientes a estructuras prehispánicas. Sobre los materiales de construcción se tienen:

Techos de paja y palma y los edificios bajos estantes de palo, que son como mármoles, y las cercas de caña gruesa como una lanza jineta ligadas con unos sarmientos o bejucos de que está esta tierra proveída: son a esta causa las casas de mucho riesgo de fuego y viento; entra el viento en ellas y sale con mucha facilidad, porque cercadas quedan como celosías transparentes y no se pueden cerrar ni embarrar por causa de la mucha humedad [...] Dura una casa de estas, siendo bien edificada y los materiales de sazón doce y catorce años, al cabo de los cuales acontece mudar solamente la techumbre o algún poste o vara, si acaso de ello hay necesidad, y de esta suerte dura veinte años (Vasco Rodríguez y Melchor Alfaro de Santa Cruz, 1981: 430).

Al contar la villa de la Victoria con una iglesia, damos cuenta de la existencia de uno o varios panteones, los cuales contarían con una gran cantidad de restos óseos caucásicos producto de más de 100 años de vida en la villa. Las mismas fuentes refieren el hecho de que en la actualidad contaríamos con una mayor cantidad de entierros de los que podemos pensar, ya que era común que por ser una zona portuaria toda la costa de Tabasco, así como por las condiciones climáticas de nortes y huracanes, hubiera naufragios completos de navíos. Se sabe que para el año de 1570 naufragó un navío en el que murió Alonso Maldonado, adelantado de Yucatán junto con su familia y 56 personas más que fueron enterradas en el atrio de la iglesia de la Victoria (Cibeira, 1972: 25).

\section{Resultados preliminares de un rescate arqueológico en la región de Frontera}

En septiembre de 2002, con motivo de las obras de ampliación del sistema carretero del estado de Tabasco, se realizó un rescate arqueológico en la carretera Villahermosa-Ciudad del Carmen, en el tramo que va del km. 69+500 al km. $72+200$, y frente a Frontera, cabecera municipal de Centla. Las excavaciones producto de este rescate fueron dirigidas por el arqueólogo José Luis Romero del INAH-Tabasco, en un trabajo que tomó aproximadamente dos meses.

Como resultado de esta intervención se reportaron distintos asentamientos arqueológicos, como San Román, Carrillo Puerto Centro, Carrillo Puerto Sur y Carrillo Galileo, todos, ubicados en la margen occidental del río Grijalva, y de los cuales se recuperó una muestra considerable de material prehispánico e histórico (cerámica, lítica, concha, hueso, metal, vidrio y fragmentos de mampostería). Las investigaciones llevadas a cabo en la región por Berlin (1956), Müller (1967), Fernández Tejedo et al. (1988: 33-38) y el acervo de materiales recuperados, despertó mi interés en el estudio de las distintas etapas de ocupación que 
se sucedieron en la zona. Posteriormente, con la autorización del titular del proyecto y del INAH-Tabasco, pude acercarme a la colección para comenzar su análisis.

El rescate arrojó material cerámico muy interesante desde un punto de vista regional, cuyo estudio y clasificación permitirán establecer una secuencia cerámica para la región de Frontera, ligada directamente al desarrollo que tuvieron los grupos mayas previos a la conquista, por lo menos desde el Preclásico Tardío, y hasta los grupos españoles establecidos en la región después de 1524, que es cuando se tiene el primer registro histórico de ocupación española en Tabasco.

El análisis inicial de la cerámica arrojó resultados preliminares acerca de la secuencia cerámica del área, así como de ciertos aspectos relacionados con el comercio e intercambio de la región, con otras regiones del área maya, como la península de Yucatán, y de otras áreas de Mesoamérica como la Costa Centro de Veracruz, y con el Altiplano Central.

De esta manera, para la región que ocupan los sitios arqueológicos antes mencionados, la ocupación humana data por lo menos desde el Preclásico Tardío, ya que se encuentra cerámica de la Vajilla Paso Caballo Ceroso (Smith y Gifford, 1965), representada por la cerámica de los grupos Sierra, Polvero y Flor Crema. Presenta además cerámica de los Grupos Sapote y Achiote, de la Vajilla Uaxactún sin Engobe (Smith y Gifford, 1965) (figura 14).

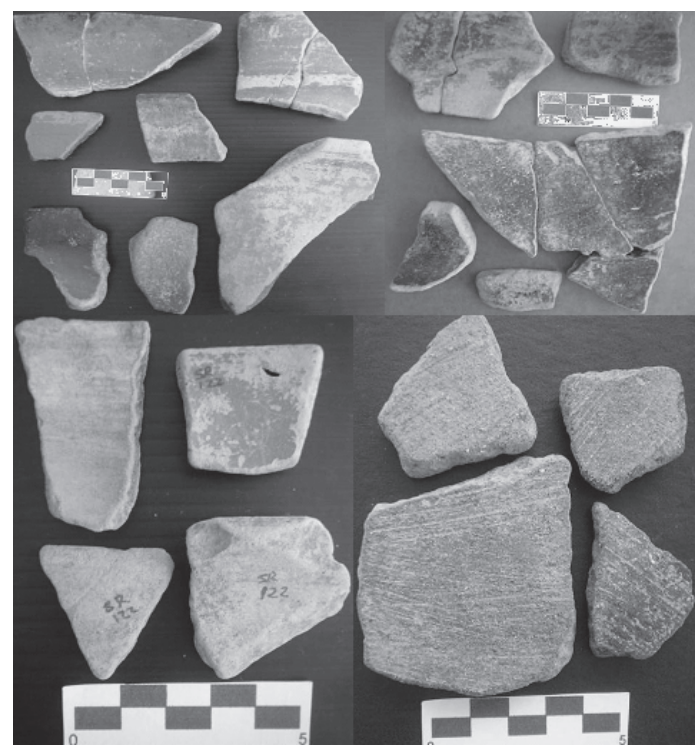

Figura 14. Cerámica de los grupos Sierra, Polvero, Flor Crema y Sapote 
Para el Clásico Temprano se cuenta con las cerámicas de los grupos Águila, de la Vajilla Petén Lustroso (Smith y Gifford, 1965) y Jilón (Matheny, 1970) (figura 15).

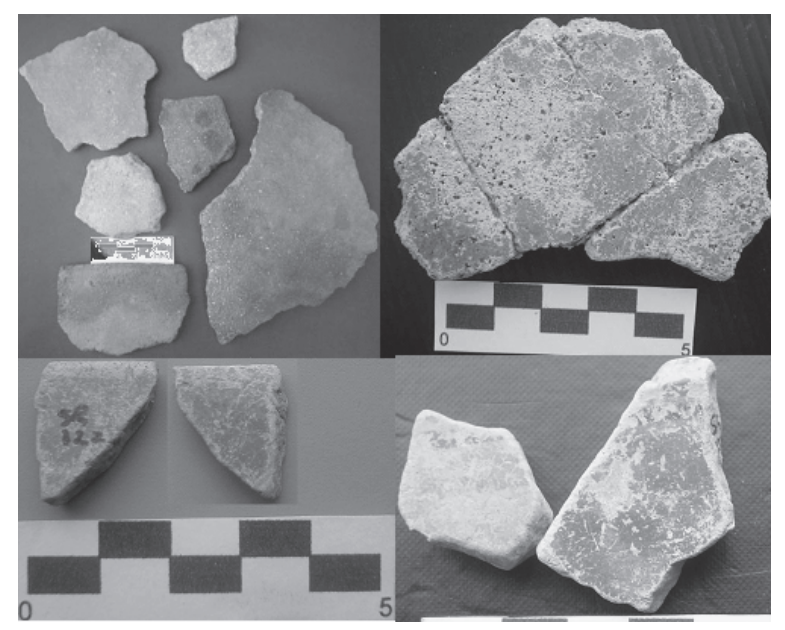

Figura 15. Cerámica de la Vajllla del Clásico Temprano: Jilón desgrasante de concha, de Matheny

Para el Clásico Temprano se cuenta con cerámicas de los grupos Centla y Cimatan, de la Vajilla Comalcalco Burdo (Peniche Rivero, 1973: 53), Balancán (Smith, 1971: 19), Comalcalco Negro (Peniche Rivero, 1973: 63), y cerámica de la Vajilla Ixpuhil Pizarra (Ball, 1977: 37), entre otras cerámicas aún por identificar (figura 16).

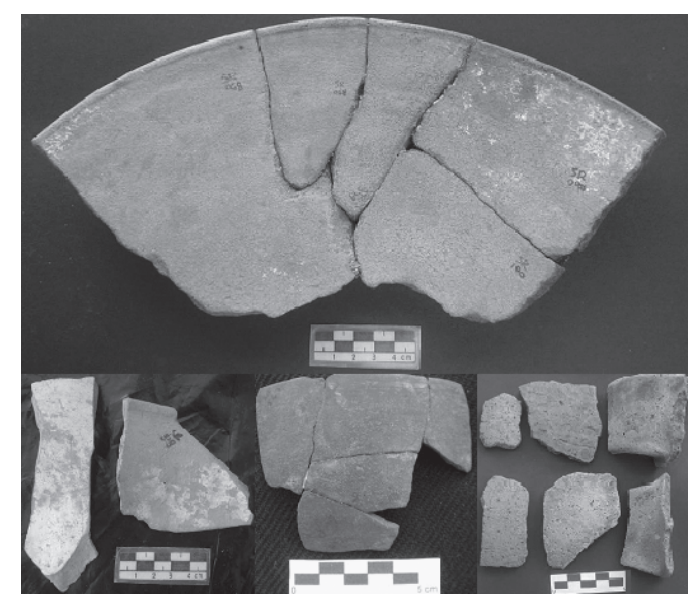

Figura 16. Cerámica de los grupos Centla, Balancán, Jalpa e Ixpuhil Pizarra 
Para el período Posclásico, las cerámicas excavadas pertenecen a los grupos Matillas (Smith, 1971: 20), Cunduacán (Smith, 1971: 20), Aguacatal (Matheny, 1970: 89-90) (figura 17).

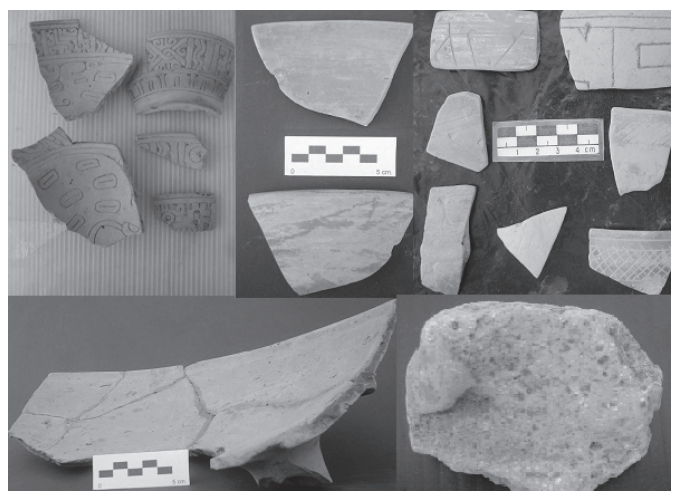

Figura 17. Cerámica de los grupos Matillas, Cunduacán y Aguacatal

Respecto a la cerámica que se pudo ubicar como cerámica de intercambio, o proveniente de otras regiones fuera del área Maya, se tiene la cerámica del grupo Mama (Smith, 1971: 23), proveniente de la costa oriental de Yucatán, y Quiahuiztlan II (Medellín Zenil, 1960: 153), y Luna Natural (Daneels, 1996: 63-64), los cuales son tipos cerámicos asociados a la Costa de Veracruz. Parece ser que el tipo Torres Policromo fue una cerámica de comercio; Sisson (1976: 455) afirma que el tipo Torres Policromo parece tener toda la tradición de la cerámica proveniente de Cholula en el Altiplano Central, perteneciente a la familia de la Cerámica Laca Policroma del Posclásico Tardío, todavía en uso poco antes de la llegada de los españoles (figura 18).

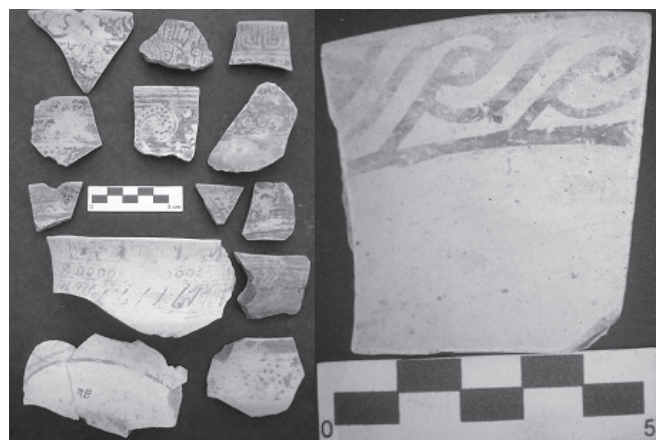

Figura 18. Tipos cerámicos Torres Policromo y Quiahuiztlan II 
Del período Colonial Temprano, no se había logrado obtener material arqueológico diagnóstico de la ocupación española en Tabasco (inmediatamente posterior a la Conquista), y que en escala aún mucho mayor apunta a la ubicación de Santa María de la Victoria. Como evidencia de la presencia española en Tabasco, se cuenta con materiales diagnósticos de manufactura española, para la segunda mitad del siglo xvı y la primera mitad del siglo xvı, dichos tipos son: Sevilla Azul/ Azul, Caparra Azul, Ciudad de México Verde/Crema, Santo Domingo Azul/Blanco, Columbia Liso, Yayal Azul/Blanco y restos de porcelana China (Goggin: 1968, 1970; Lister y Lister: 1982; Fournier: 1990) (figura 19).

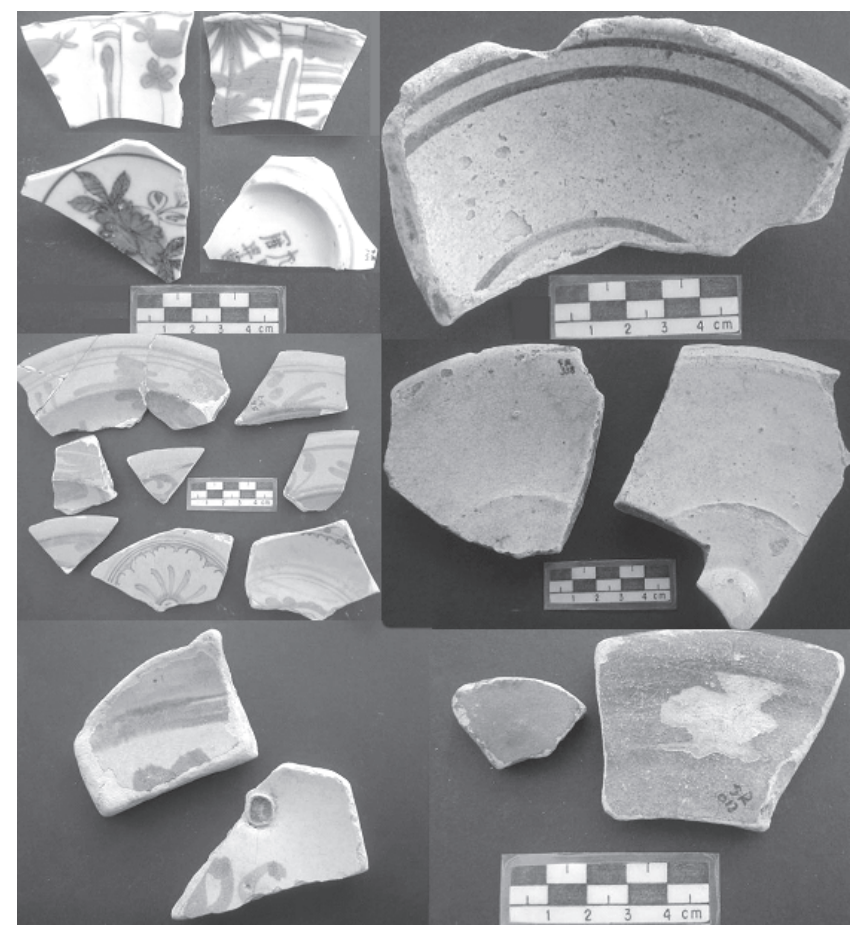

Figura 19. Tipos cerámicos Colonial Temprano: Porcelana China, Yayal Azul/Blanco, Sevilla Azul/ Azul, Columbia Liso, Santo Domingo Azul/Blanco y Caparra Azul. Todos tipos cerámicos diagnósticos desde el período de contacto, hasta la segunda mitad del siglo xvII

\section{Conclusiones}

Aunque el área de Frontera no cuenta con un estudio detallado a nivel regional, hay indicios arqueológicos e históricos de que grupos chontales se asentaron en 
toda el área, y establecieron su capital, de acuerdo con las mismas fuentes históricas, en un área próxima al puerto de Frontera, específicamente en alguna parte sobre el arroyo El Trapiche, localizado frente a la ciudad de Frontera, y muy cerca de la línea de la carretera y el puente que cruza el río Grijalva, según los resultados previos al análisis de la cerámica excavada.

Desde el Clásico Temprano existe evidencia de una gran ocupación en el área, la cual servia como un punto de control de rutas marítimas y fluviales, que controlaba los chontales desde Frontera, el comercio con las sierra de los Cimatanes, en lo que se piensa fue todo un corredor comercial desde tierras zoques, en Tecominoacán, Mecatepec, Ocuapan, Huimanguillo y Pichucalco (Jiménez, 1987:40). Dicho corredor transportaba e intercambiaba mercancías con el Altiplano Central, bifurcándose también desde Huimanguillo hacia el río MezcalapaGrijalva; el cual corre hacia la costa, y desde donde quienquiera que controlara su tránsito, controlaba también la ruta comercial que se dirigía hacia el noroeste y noroeste del Golfo de México, y finalmente, hacia la península de Yucatán.

La zona del rescate arqueológico fue el escenario del primer enfrentamiento militar entre fuerzas españolas e indígenas, como antecedente de la guerra de conquista de México. Posteriormente en este mismo lugar se fundó la primera capital española de la provincia de Tabasco. Es posible que alguno de los sitios excavados corresponda a los sitios arqueológicos mencionados en las fuentes históricas, en virtud de la presencia de materiales arqueológicos atribuidos a los grupos que aparecen mencionados en ellas (españoles e indígenas), pertenecientes tal vez a Potonchán o Santa María de la Victoria.

El análisis de la cerámica recientemente excavada en San Román sirve de excelente referente para el estudio de la problemática histórica en torno a la última capital prehispánica de Tabasco, y a la primera capital hispana de la provincia. Eventos tanto sociales como naturales han llevado a la región a sufrir cambios drásticos en cuanto a su composición fisiográfica, los cuales no han hecho más que dificultar las condiciones bajo las cuales los arqueólogos e historiadores han planteado los argumentos que sirven para establecer una probable solución a este "histórico, problema histórico".

En un futuro cercano sería ideal poder realizar una mayor cantidad de trabajos arqueológicos, más allá de rescates y salvamentos, tan comunes en el área. Estos trabajos podrían reorientar el rumbo de la concepción histórica de la costa de Tabasco desde tiempos prehispánicos hasta la Colonia en México. Dejar de buscar en los libros y forzar descripciones histórico-geográficas de una geografía alterada, y por lo tanto, diferente a la geografía moderna del área, será una necesidad para los historiadores, para que en un trabajo conjunto entre arqueólogos y geomorfólogos la prioridad no sea sólo excavar y ensuciarnos las manos, sino explicar desde varias perspectivas un problema histórico tan complejo, que ha tomado más de 100 años poder ser siquiera abordado. 


\section{BIBLIOGRAFÍA}

Adams, Richard

1971 The Ceramics of Altar de Sacrificios. Massachussets, Peabody Museum of Cambridge.

Andrews, Anthony

1998 "El comercio marítimo de los mayas del Posclásico", La navegación entre los mayas, Arqueología Mexicana, VI (33): 16-23. México: Editorial Raíces-Conaculta.

Ball, Joseph W.

1977 The Archaeological Ceramics of Becán, Campeche, México. Nueva Orleáns: Middle American Research Institute, Tulane University (Publication 43).

Berlin, Heinrich

1956 Late Pottery Horizons of Tabasco, México. Washington: Carnegie Institution (Publication 606).

Blom, Frans

1926 Tribes and Temples: A Record of the Expedition to Middle America conducted by The Tulane University of Louisiana in 1925. Nueva Orleáns: Tulane University of Louisiana, 2 vols.

Cabrera, Bernat y Ciprián Aurelio

1987 Viajeros en Tabasco: Textos. Tabasco: Gobierno del Estado de Tabasco.

Cabrera, María del Refugio y Jesús Vargas Ramírez

1985 Acercamiento a los chontales de Tabasco. Manuscrito entregado al CIESASGolfo y a la Biblioteca Nacional de Antropología e Historia del INAH. México.

Chavero, Alfredo

1940 México a través de los siglos. Historia general y completa del desenvolvimiento social, político, religioso, militar , artístico, científico y literario de México, desde la antigüedad más remota hasta la época actual. Publicada bajo la dirección del General D. Vicente Riva Palacio. Gustavo S. López, editor, México.

Chávez Jiménez, Ulises

2002 "Santa María de la Victoria: 361 años de historia olvidada en Tabasco", ponencia presentada en el Primer Premio a la Excelencia Académica: Carlos Navarrete Cáceres, 10 de junio, ENAH, México.

2005 Potonchán y Santa María de la Victoria. Una propuesta arqueológica a un problema histórico, ponencia presentada en el XV Encuentro Internacional "Los Investigadores de la Cultura Maya”, 9 de noviembre, Campeche: UACAM. 
Chávez Jiménez, Ulises

2006 "De mayas chontales, españoles y pantanos: la secuencia cerámica de San Román, Tabasco”. Tesis de licenciatura en Arqueología. México: ENAH.

Cibeira Taboada, Miguel

1972 Historia de Tabasco; Relación de la Villa de Santa María de la Victoria, Boletín Bibliográfico Rubín de la Borbolla. México: Universidad Autónoma Juárez de Tabasco.

Cortés, Hernán

1963 Cartas de Relación, $7^{\text {a }}$ ed., México: Porrúa.

1988 Cartas de Relación, 15ª ed., México: Porrúa.

Daneels, Annick

1996 "Proyecto Atoyaquillo. Informe de Cerámica. Rescate Centro INAH-Veracruz, Paraje Nuevo, Veracruz", primavera de 1995. Informe entregado al Consejo de Arqueología.

Díaz, Juan

1972 Itinerario de la Armada de el rey católico a la isla de Yucatán en las Indias, en el año 1518 en la que fue por comandante y capitán general Juan de Grijalva Escrito, para su Alteza por el Capellán de la dicha Armada, comentarios Jorge Gurría Lacroix. México: Juan Pablos.

Díaz del Castillo, Bernal

1970 Historia verdadera de la conquista de la Nueva España. México: Porrúa.

Fernández Tejedo, Isabel et al.

1988 Zonas arqueológicas de Tabasco. Tabasco: INAH-Gobierno del Estado.

Fournier, Patricia

1990 Evidencias arqueológicas de la importación de cerámica en México, con base en los materiales del exConvento de San Gerónimo. México: INAH (Colección Científica, 213).

Fowler Jr., William R.

1989 The Cultural Evolution of Ancient Nahua Civilization: The Pipil-Nicarao of Central America. Norman, Oklahoma: University of Oklahoma Press.

Gallico, Sonia

2000 Guía arqueológica de Ostia Antica. Roma: ATS Italia Editione.

Gasco, Janine y France Berdan

2003 "International trade centers", The Posclassic Mesoamerican World, pp. 110116, Michael Smith y France Berdan (eds.). Salt Lake City: The University of Utah Press. 
Gil y Sáenz, Manuel

1979 Compendio histórico, geográfico y estadístico del estado de Tabasco. México: Consejo Editorial del Estado de Tabasco.

Goggin, John M.

1968 Spanish Majolica in the New World: Types of the Sixteenth to the Eighteenth Centuries. New Haven: Yale University Press (Publications in Anthropology, 72).

1970 "The Spanish olive jar. A preliminary study", Papers in Caribbean Anthropology. Sydney W. Mints (comp.), núm. 57-64, reimpreso por Human Relations Area Files Press. New Haven: Yale University Press (Publications in Anthropology, 62).

González, Pedro

1981 Los ríos de Tabasco. México: Consejo Editorial del Estado de Tabasco.

Guzmán V. Raquel

1982 Atlas histórico de Tabasco. 1570-1981. México: Consejo Editorial del Estado de Tabasco.

INEGI

1986 Síntesis geográfica, nomenclátor y anexo cartográfico del estado de Tabasco. México.

2000 Cuaderno estadístico municipal. Centla, Tabasco, Gobierno del Estado de Tabasco, H. Ayuntamiento Constitucional de Centla, México.

2000 Carta geológica 1:50 000. Frontera, Tabasco E15-5. México.

2000 Carta hidrológica de aguas subterráneas. 1:50 000. Frontera, Tabasco E15-5. México.

2000 Carta de suelos. 1:50 000. Frontera, Tabasco E15-5. México.

Izquierdo, Ana Luisa

1995 El abandono de Santa María de la Victoria y la fundación de San Juan Bautista de la Villahermosa. México: UNAM, IIFL, Centro de Estudios Mayas.

1997 Acalán y la Chontalpa en el siglo xvı, su geografía política. México: UNAM, IIFL, Centro de Estudios Mayas.

2005 "Historia de dos fundaciones: Santa María de la Victoria y San Juan Bautista de Villahermosa”, Tabasco: Antiguas Letras, Nuevas Voces, pp. 91-115, Mario Humberto Ruz (ed.). México: UNAM, IIFL, Centro de Estudios MayasUACSHUM.

Jiménez Valdez, Gloria Martha

1987 Informe de los pueblos de la Chontalpa Central. Un reconocimiento prelimi- 
nar. Consejo de Arqueología, carpeta 3, vol. 26-13. Archivo Técnico, Dirección de Monumentos Prehispánicos. INAH, México.

Jones, Grant D.

1998 "Itza-Spanish encounters, 1526-1690", The Conquest of the Last Maya Kingdom, pp. 29-59. California: Standford University Press.

Krynine, Paul

1939 Depósitos de arcosas en el trópico húmedo. Informe de la Standard Oil Company of California, Yale University.

Landa, fray Diego de

2003 Relación de las cosas de Yucatán, edición y comentarios Miguel Rivera Dorado. España: Promo Libro (Colección Crónicas de América).

Lister, Florence y Robert Lister

1982 Sixteenth Century Majolica Pottery in the Valley of México. Tucson: University of Arizona Press.

López Reyes, Diógenes

1979 Historia de Tabasco. México: Consejo Editorial del Estado de Tabasco.

Masson, Marilyn

2001 "La dinámica del proceso de maduración de la organización del estado en la sociedad Posclásica", Los mayas, una civilización milenaria, pp. 341-353, Nikolai Grube (ed.). Bonn: Könemann.

Matheny, Ray

1970 The Ceramics of Aguacatal, Campeche, México. Provo, Utah: New World Archaeological Foundation, Brigham Young University.

Medellin Zenil, Alfonso

1960 Cerámicas del Totonacapan. Xalapa: Universidad Veracruzana.

Müller, Florencia

1967 Atlas arqueológico de Tabasco, Archivo Técnico, Índice 3: 26-34. Informe. Dirección de Monumentos Prehispánicos, INAH, México.

Ortiz Ortiz, Martín

1988 Las vías de comunicación terrestre y la historia de Tabasco, desde la época prehispánica hasta 1850. México: Gobierno del Estado de Tabasco, Secretaría de Educación, Cultura y Recreación, Dirección de Educación Superior e Investigación Científica.

Peniche Rivero, Piedad

1973 “Comalcalco, Tabasco: su cerámica, artefactos y enterramientos”. Tesis de licenciatura en Arqueología. México: UADY. 
Relaciones histórico-geográficas de la Provincia de Tabasco

1983 Relaciones histórico-geográficas de la gobernación de Yucatán (Mérida, Valladolid y Tabasco), pp. 346-432, Mercedes de la Garza (coord.). México: UNAM. IIFL, Centro de Estudios Mayas (Fuentes para el Estudio de la Cultura Maya, 1).

Rodríguez, Vasco y Melchor Alfaro de Santa Cruz

1983 "Relación de la provincia de Tabasco", Relaciones histórico-geográficas de la gobernación de Yucatán (Mérida, Valladolid y Tabasco), pp. 415-432, Mercedes de la Garza (coord.). México: UNAM, IIFL, Centro de Estudios Mayas (Fuentes para el Estudio de la Cultura Maya, 1).

Rovirosa, José

1946 Ensayo histórico sobre el río Grijalva. México: Gobierno Constitucional de Tabasco, (Contribución de Tabasco a la Cultura Nacional, 7).

Ruz, Mario Humberto, et al.

2000 El magnifico señor Alonso López, Alcalde de Santa María de la Victoria y aperreador de indios, Tabasco 1541. México: UNAM, IIFL, Centro de Estudios MayasPlaza y Valdez.

Salazar Ledesma, Flora Leticia

2003 "Los ríos perdidos. Río Grijalva-Mezcalapa, problemática de su nomenclatura”, Los Investigadores de la Cultura Maya, 11, vol. II: 524-547. Campeche: Universidad Autónoma de Campeche.

Salazar Ledesma, Flora Leticia y Ulises Chávez Jiménez

2005 "Santa María de la Victoria: Primer asentamiento español del siglo xvı", Tabasco: Antiguas letras, nuevas voces, pp. 61-90, Mario Humberto Ruz (ed.). México: UNAM, IIFL, Centro de Estudios Mayas-UACSHUM.

Santa Anna, Justo Cecilio

1979 Notas para la historia de la agricultura en Tabasco. México: Consejo Editorial del Gobierno del Estado de Tabasco.

Santamaría, Francisco

1988 Diccionario general de americanismos, $2^{\mathrm{a}}$. ed., Tabasco: Gobierno del Estado, 3 tomos.

Scholes, France V. y Ralph Roys

1996 Los chontales de Acalán-Tichel, edición al español Mario Humberto Ruz, traducción Mario Humberto Ruz y Rosario Vega. México: UNAM, IIFL, Centro de Estudios Mayas-CIESAS.

Sisson, Robert

1976 Survey and Excavation in the Northwestern Chontalpa, Tabasco, Mexico. Cambridge: Harvard University. 
Smith, Robert Eliot

1971 The Pottery of Mayapan. Including Studies of Ceramic Material from Uxmal, Kabah, and Chichen Itza. Cambridge: Harvard University Press (Papers of the Peabody Museum of Archaeology and Ethnology, 66).

Smith, Robert y James Gifford

1965 "Pottery of the Maya Lowlands", Hand Book of Middle American Indians, vol. 2, pp. 500-504. Austin: University of Texas Press.

Spinden

1975 A Study of Maya Art. Its Subject, Material and Historical Development, introducción Eric Thompson. Nueva York: Dover Publications.

Solís, Antonio de

1999 "De cómo inicia Cortés la conquista de México”, Historiadores de las Indias, pp. 159-161. México: Conaculta.

Thompson, J. Eric S.

2004 Historia y religión de los mayas. México: Siglo XXI.

Ugalde, José

1916 Informe de la localización de la zona arqueológica de Cintla, Tabasco. Archivo Técnico, INAH. Clasificación 826-2. Archivo Técnico. Dirección de Monumentos Prehispánicos. INAH, México.

1919 Informe sobre la historia de Tabasco. Desde la época prehispánica, colonial y la Independencia. Archivo Técnico, INAH. Clasificación 832.8. Archivo Técnico. Dirección de Monumentos Prehispánicos. INAH, México.

Vargas, Ernesto

2001 Itzamkanac y Acalán. Tiempo de crisis anticipando el futuro. México: UNAM, Instituto de Investigaciones Antropológicas.

West, Robert, N. P. Psuty y B. G. Tom

1969 The Tabasco Lowlands of Southeastern Mexico. Baton Rouge: Louisiana State University Press. 